\title{
A Simplified Approach to Estimate the Ultimate Longitudinal Strength of Ship Hull
}

Hsin-Chuan Kuo

Associate Professor, Department of System Engineering and Naval Architecture, National Taiwan Ocean University, 2, Peining Road, Keelung, Taiwan 202.

Jiang-Ren Chang

Associate Professor, Department of System Engineering and Naval Architecture, National Taiwan Ocean University, 2, Peining Road, Keelung, Taiwan 202., cjr@sena.ntou.edu.tw

Follow this and additional works at: https://jmstt.ntou.edu.tw/journal

Part of the Engineering Commons

\section{Recommended Citation}

Kuo, Hsin-Chuan and Chang, Jiang-Ren (2003) "A Simplified Approach to Estimate the Ultimate Longitudinal Strength of Ship Hull," Journal of Marine Science and Technology. Vol. 11: Iss. 3, Article 2.

DOI: $10.51400 / 2709-6998.2272$

Available at: https://jmstt.ntou.edu.tw/journal/vol11/iss3/2

This Research Article is brought to you for free and open access by Journal of Marine Science and Technology. It has been accepted for inclusion in Journal of Marine Science and Technology by an authorized editor of Journal of Marine Science and Technology. 


\section{A Simplified Approach to Estimate the Ultimate Longitudinal Strength of Ship Hull}

\section{Acknowledgements}

The authors would like to express their thanks to the United Ship Design and Develop Center for their financial support under Contract Number: USDDC- 221 


\title{
A SIMPLIFIED APPROACH TO ESTIMATE THE ULTIMATE LONGITUDINAL STRENGTH OF SHIP HULL
}

\author{
Hsin-Chuan Kuo* and Jiang-Ren Chang**
} $\begin{array}{ll}\text { Key words: } & \text { simplified approach, ultimate longitudinal strength, hull girder, } \\ \text { stiffened panel. }\end{array}$

\begin{abstract}
In this paper, the calculation of the ultimate longitudinal strength of the ship hull is revisited. A simplified approach dealing with the longitudinal ultimate strength of ship hull has been developed and an effective numerical program is implemented based on the individual components of ship structures. It is, then, possible to find the ultimate strength of the whole ship structure by evaluating those individual components. Comparisons of numerical results from the proposed approach and published literatures are conducted for further validation. Since relative errors of calculations of the current approach to the literature with respect to the experimental data are within $3 \%$, it is shown that the proposed approach can be adopted for the estimation of the ultimate bending strength of ship hull in sagging or hogging condition with and without at fully plastic state. In addition, a comparison between the numerical result and the existing expression for a very large crude carrier also shows that the proposed approach is not only as accurate as those published literatures but also more available. Therefore, the proposed approach with the numerical program is quite suitable to be adopted in the preliminary design of ship structure due to its accuracy and simplicity.
\end{abstract}

\section{INTRODUCTION}

In the past three decades, a great deal of activity has taken place for predicting, in a realistic manner, the sea loads to which the ship hull girder is subjected. The main initiative behind these activities is the possible deficiencies in the standard calculations of the longitudinal bending moments, particularly under certain circumstances. The ultimate strength of ship structures has been considered very important in the societies of classification and academic research since the loads acting on the ship hull are uncertain due to rough seas or unusual loading and unloading of cargoes during operations. Several potential forms of catastrophic

Paper Submitted 06/17/03, Accepted 08/12/03. Author for Correspondence: Jiang-Ren Chang.E-mail: cjr@sena.ntou.edu.tw

Associate Professor, Department of System Engineering and Naval Architecture, National Taiwan Ocean University, 2, Peining Road, Keelung, Taiwan 202. "collapse" have been identified as responses to an excessive hull girder bending moment. These may take place, presumably, with but a single application of load so that the possibility of their occurring must be weighted against the extreme or worst likely load value. In additions, because aging ships may have suffered damages due to hull corrosion and fatigue, their structural resistance may weaken and further collapse under applied loads even smaller than designed loads.

The conventional longitudinal strength calculation for a ship mainly concerns the elastic response of hull girder due to an assumed wave load and then, the elastic section modulus of hull girder, which is taken as the primary surveying index of the longitudinal bending strength, can be achieved by using the linear bending theory. However, this criterion may fail when two ships having identical section modulus with the same materials may have different bending strengths due to differing resistance to buckling of the compressed parts of girder sections.

With the full scale structural tests, Vasta [44] found that a close correlation between the ultimate bending strength of the hull and the buckling strength of the compressed parts of the hull plating exists and proposed that the limiting bending moment of longitudinally framed hull should be the product of the section modulus and the ultimate stress of plating panels. This formula is simple; however, it takes no account of buckling effects from compressed parts. With a comparison to the conventional elastic bending theory, Caldwell [5], therefore, developed the "limit design" ideas and introduced the concept of a structural instability strength reduction factor for strength calculations. However, only calculation with a statical condition of loading may not be conformity with the real dynamic loading of the girder. In additions, although the buckling effect has been included in calculation, it may not be permissible to replace the distribution of longitudinal compression by an equivalent average ultimate longitudinal compression since the buckling phenomenon depends on the stability of structures and has little or no connection with a "mean stress". Nevertheless, when 
the buckling characteristics are found with more researches in this field, a modification to the formulae will enable the ultimate moment of resistance to be found [5]. Cladwell [5] could be the first one to incorporate the buckling effects into the ship strength assessment. Since then, subsequent progress has been made in the fields of buckling as well as final collapse studies of structures [6, 11-13, 22, 30], and reliable estimates [18, 19, 43] have been emerged for analyzing the collapse strength and their post-collapse behaviors. However, those algorithms, used for calculating the ultimate longitudinal strength of the ship hull girder, usually differ one another due to their different assumptions, and lack of accurate modeling of the hull girder results in unreliable results even in the case of an experimental investigation [32].

Following with Caldwell's research, Faulker et al. [13] proposed a reasonable method to calculate the structural instability strength reduction factor and improved formulations became available for critical stress corresponding to various modes of compression failures. Progressive research on post-buckling strength of stiffened panels inspired Dow et al. [10] to develop ways of estimating average stress-strain characteristics up to compressive strain. By incorporating buckling behavior models into an overall analysis of the hull girder as the bending curvature increases, Smith [42] also proposed the incremental curvature procedures to calculate the derivation of moment-curvature relationship for a complete hull. Although some applications $[4,8]$ of this approach have demonstrated its general feasibility with comparisons to model experiments; however, in our opinion, some calculating schemes, mainly based on the finite element formulations, need much time consumption and the plate element strength reached by way of empirical curves might lead to inaccuracy.

An engineering approach [4] considering a simplified analysis model for each individual beam-column element was proposed to calculate the strength of the hull girder by the linear superposition of individual contributions of elements. Based on a flexural-torsional buckling formulation, Adamahak [1] developed an approximate method in a computer program and obtained curves of moment-curvature for the calculation of ultimate strength of panels. Therefore, at this stage, the assessments on the longitudinal strength of the ship girder were focused on the collapse strength of an individual panel structure and the ability to predict moment-curvature relationships.

Later, two simplified expressions were further proposed to explore the ultimate moment of the stiffened panel in comparisons with experimental results by introducing a dynamic relaxation method [29]. Besides, in order to estimate the ultimate longitudinal bending moment of ships, Hughes [25] proposed a simpler approximating method with a rationally based structure design concept, which does not neglect any reserve of panel compressive strength until its maximum resistance has been reached. The accuracy of this method, based mainly on the panel strength analysis, was demonstrated by a comparison with several experimental results and it first led the optimal concept to ship structural designs. However, ignoring such a contribution of the post-collapse resistance of compressed panels makes the evaluation of the ultimate strength of a redundant structural system impossible. It should be noted that, in this method, discrete steps from one element collapse to the next was suggested instead of applying regular small increments of curvature.

By adopting most positive features of the abovementioned works with introducing new stress-strain relationships, Rahman and Chowdhury [40] developed a computing methodology for the ultimate value of the longitudinal bending moment at any cross section of a ship or a box girder. The cross section was modeled as one stiffener with its associate effective plating. They claimed that limit states of these panels, either tensile or compressive, were modeled in an appropriate manner since the ultimate strength of the girder section is mainly governed by the behavior of panels under compression. Special attention was also driven to the collapse and post-collapse behavior of these panels. The computing program was ever validated by calculating the ultimate longitudinal bending moment of a very large crude carrier (VLCC) which "broke its back" during discharge of oil in 1980. The ultimate longitudinal strength calculation, which put emphasis on modeling of the buckling and post-buckling behavior of compressed parts of the same actual ship, was also reported [41] and showed that both the calculation and provision of longitudinal strength are in excess of normal requirements for the ship in both hogging and sagging conditions. Following with previous studies $[4,18,19,41]$ and especially with respect to plate strength and beamcolumn behavior, Gordo et al. [17] also presented an approximate assessment of the ultimate longitudinal strength of the hull girder. The method was also checked by comparing its predictions with those of Ref. [41] for the VLCC and then further used to study effects of residual stresses, corrosion and combined bending for illustrating its capability. The proposed method reveals sound results as compared to those obtained by using finite element programs.

Since Smith [42] first proposed an approach, which was a hybrid method of the finite element scheme with the load-deformation curves, to calculate the performance of each individual element for the hull girder and as the numerical capability of a computer grows fast, 
alternative methods in the field to predict the ultimate strength can be grouped into simplified methods or methods of components $[1,4,8,10,17,23,29,35,36$, $38,40,41]$ and the finite element formulations [2, 24, 34, 46]. However, the latter were ever criticized by Gordo et al. [16] since they were proven impractical for the use of calculations at a design phase. In their paper, three important issues were emphasized; the first is that the contribution of each structural element to the moment-curve relationship of the ship hull [17] and the prediction of the method need to be validated by various experimental results [15]. The second is that, for many types of ships, the combined effect of the vertical and horizontal bending moments needs to be considered carefully since it deals with the collapse of ship hulls under the combined load effects [14, 31, 37] and it can accurately accounts for the load shortening contribution of each plate and stiffener assembly. The last is that considering the case of biaxial compressive strength of plates [20-21] leads to the proposal of the interaction equations $[14,16,31]$ to deal with the collapse of hull section under combined load effects.

Basically, when a ship subjected to the loadings and wave loads operates at sea, one can consider and categorize all the loads into the vertical bending moment, $M_{V}$, horizontal bending moment, $M_{H}$, vertical shear force, $Q_{V}$, and twisting moment, $M_{T}$, as shown in Fig. 1. Although most structural designs for merchant ships mainly concern their bending strengths owing to ratios of their geometrical dimensions as a slender structure; however, as the loading types change and oblique wave

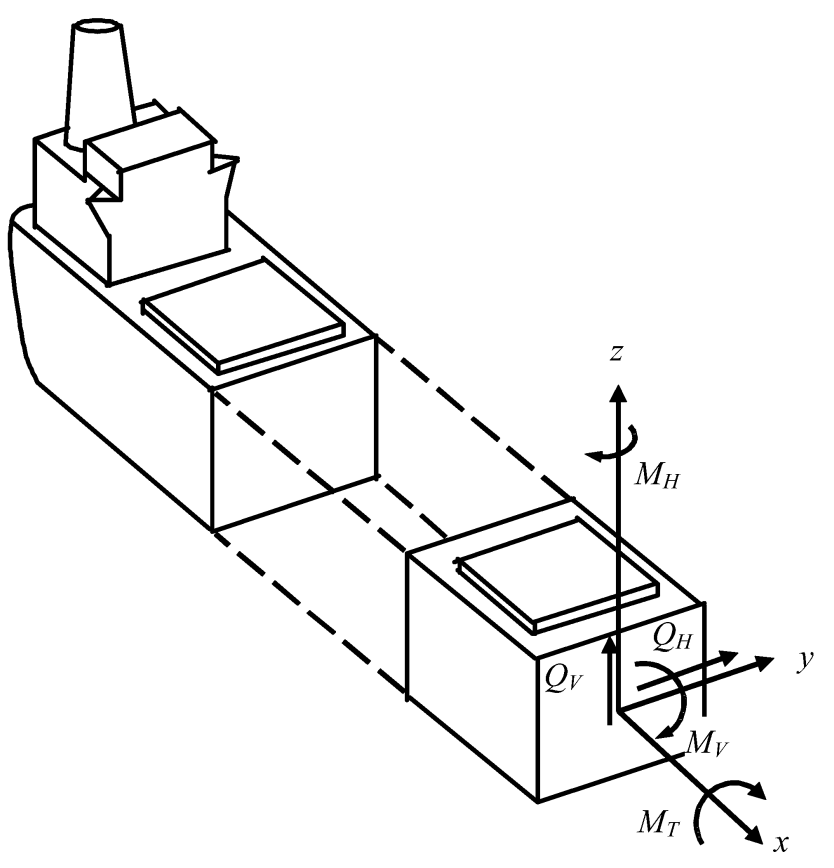

Fig. 1. Different loads applied to the hull section. arises, the other kinds of strength appear and play a crucial role in the preliminary stage, such as the shear strength for bulk carriers and the torsional strength for containers with large openings. Moreover, when the age of an available ship increases, the structural strength will reduce and how to monitor the longitudinal structural strength becomes vitally important. Besides, when the ship accident happens $[45,47]$, to evaluate or assess residual strength after collision and grounding [39] in a short time is necessary especially when the emergency rescue is requested and following operations will be implemented soon. As a result, a simplified and accurate approach to estimate the longitudinal strength of ship hull is convenient as compared with the finite element method (FEM). Therefore, based on the assumption that the strength of ship hull can be represented by the linear superposition of individual contributions of elements [4, 41], in this paper, a simplified approach with a self-developed numerical program is proposed to deal with problems of the ultimate longitudinal strength of the ship hull. Several comparisons including of a real VLCC example are also conducted to validate the proposed approach. The results show that the current approach is not only simple but also accurate enough when applying it in the preliminary phase of ship structural design.

\section{THEORETICAL BACKGROUNDS}

In general, the stresses arise due to ship hull subjected to the internal and external loads can be grouped into the compressive stress, tensile stress and shear stress; therefore, causes for failure of ship hull components can be summarized as: 1 . the excessive compressive stress leads to buckling failure mode since the buckling stress of components is lower than yielding stress of structural material and /or the initial conditions, such as the initial imperfections, residual stress and other more sensitive boundary conditions, have existed; 2. the excessive tensile stress results in yielding failure mode owing to elasto-plastic behavior of the used material; 3 . the shear stress leads to shear buckling failure mode.

\section{Buckling failure modes}

It is known that there exist four typical modes of buckling failures for ship structural members as shown in Figs. 2(a) to 2(c), of those are buckling of a plate, flexural buckling of panel stiffeners, torsional buckling or tripping of panel stiffeners, and overall buckling of the grillage. For simplification of analysis, tow basic assumptions should be noted in the followings: First, the buckling failure mode of web frame only concerns 
the plate buckling and stiffener's buckling since there usually exist large transverse frames along the ship hull such that no tripping effect arises; second, those plates with stiffeners attached to the transverse frame are

(a). Plate

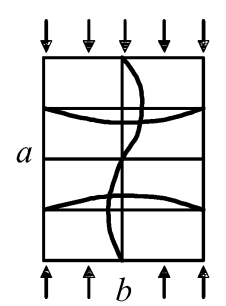

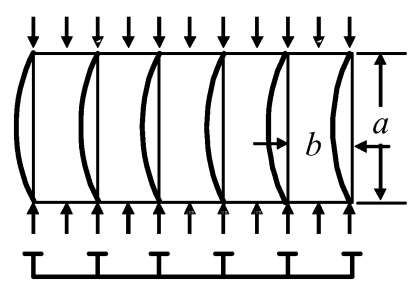

Column

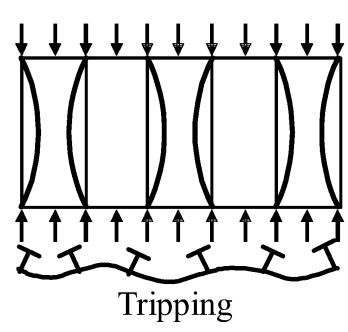

(b). Panel (c). Grillage

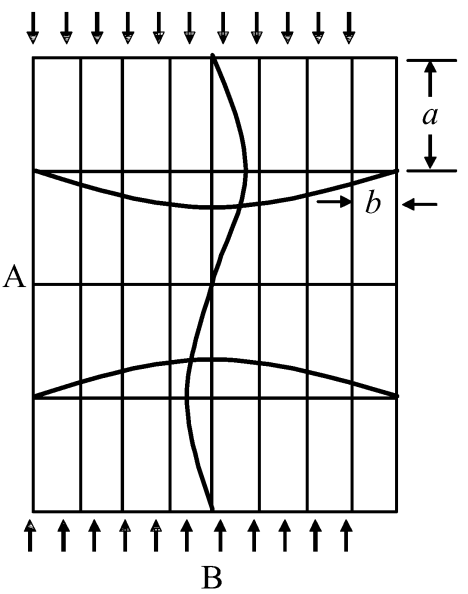

Fig. 2. Several buckling failure modes for different structural members.

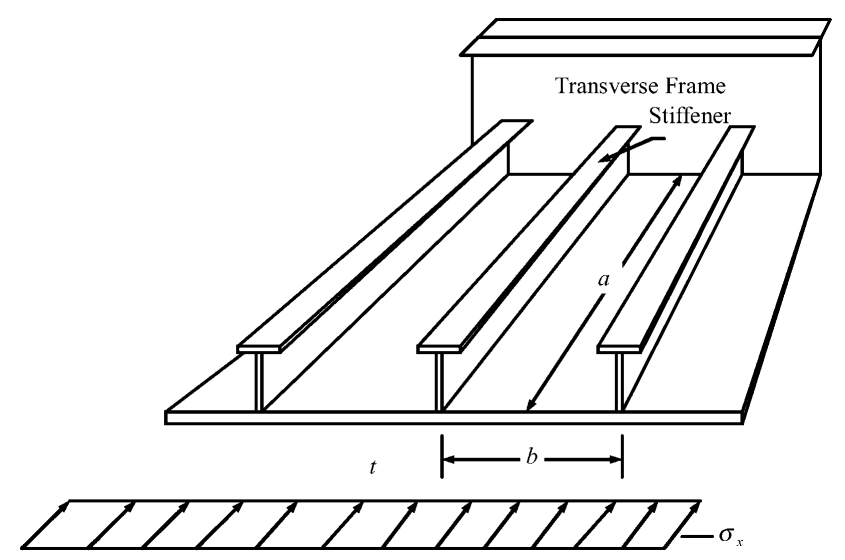

Fig. 3. A transverse frame attached with stiffened panel. subjected to axial compressive stress, $\sigma_{x}$, as shown in Fig. 3 and their buckling modes can be represented by the beam-column components as shown in Fig. 4.

\section{Approaches used to analyze those buckling failures}

Based on assumptions mentioned above, the available approaches have been proposed and can be further grouped into (a) the semi-empirical formulae, such as by Faulker [12], Faulker et al. [13], and Caelsen [6] and (b) empirical formulae by Lin [29], Paik and Mansour [35], Paik and Pedersen [36], Paik et al. [37], and Lee [27]. The self-developed numerical program of this paper is implemented by using the empirical formulae and we will give a brief introduction for the reader's convenience as follows.

\section{Lin's formula (without effective breadth)}

Lin [29] first proposed the dynamic relaxation method to derive the reduction factor of the ultimate strength of a plate with stiffeners and adopted the beamcolumn element to analyze the strength of ship structure. Among them, the width of a plate was considered effective and the section of the plate with stiffeners and the simple supported boundary conditions as well as the given loadings were described as shown in Fig. 5. The numerical calculation results are obtained by two parameters, the slender ratios of a stiffener, $\lambda_{s}$, and of a plate, $\beta$, respectively. By using the least square method, the buckling reduction factor containing the two parameters can be formulated by

$$
\phi_{u}=\frac{\sigma_{u}}{\sigma_{y}}=\left(c_{1}+c_{2} \lambda_{s}^{2}+c_{3} \beta^{2}+c_{4} \lambda_{s}^{2} \beta^{2}+c_{5} \lambda_{s}^{4}\right)^{-0.5}
$$

in which $\beta=\frac{b}{t} \sqrt{\frac{\sigma_{y}}{E}}, \lambda_{s}=\frac{a}{\pi r} \sqrt{\frac{\sigma_{y}}{E}}, \sigma_{u}$ denotes the ultimate stress of stiffened panel, $\sigma_{y}$ denotes the average yielding stress of the plate-stiffener combination, $E$
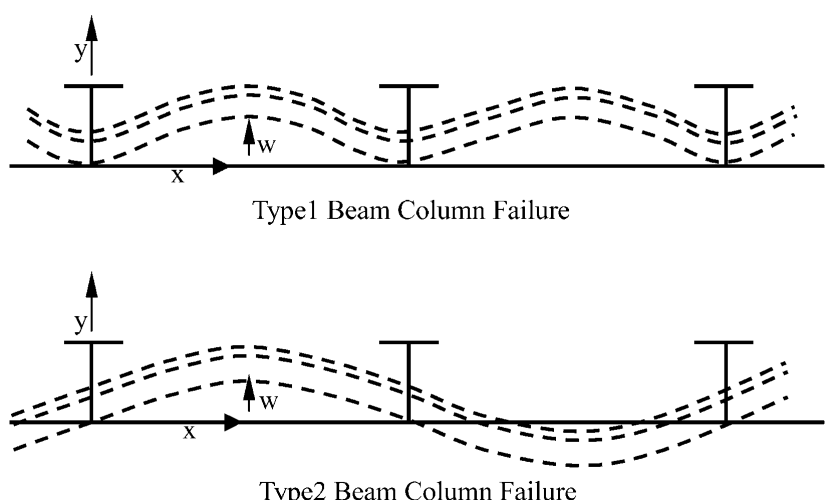

Fig. 4. Failure modes of beam-column components. 
the Young's modulus, $a$ the length of stiffeners' span between transverse girders, $b$ the width of a plate, $t$ the thickness of a plate, and $r$ the radius of gyration. The five constants in equation (1) are $c_{1}=0.960, c_{2}=0.765$, $c_{3}=0.176, c_{4}=0.131, c_{5}=1.046$, respectively.

\section{Paik's formula}

Based on Lin's work and with more numerical data, Paik et al. [37] proposed the similar expressed formula of the buckling reduction factor as

$$
\phi_{u}=\frac{\sigma_{u}}{\sigma_{y}}=\left(c_{1}+c_{2} \lambda_{s}^{2}+c_{3} \beta^{2}+c_{4} \lambda_{s}^{2} \beta^{2}+c_{5} \lambda_{s}^{4}\right)^{-0.5},
$$

in which $c_{1}=0.995, c_{2}=0.936, c_{3}=0.170, c_{4}=0.188$, $c_{5}=-0.067$, respectively.

\section{Lee's formula}

Following with Lin's research, Lee [27] adopted the beam-column model and further applied the matrix displacement method to deal with the nonlinear equilibrium equation of the elasto-plastic large deformation of a plate with stiffeners. In his work, a three-order displacement function is adopted to deal with the bending deformation from the Euler beam theory and the

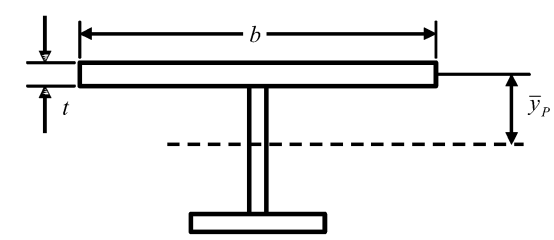

Beam-Column Formed by Plate and Stiffener

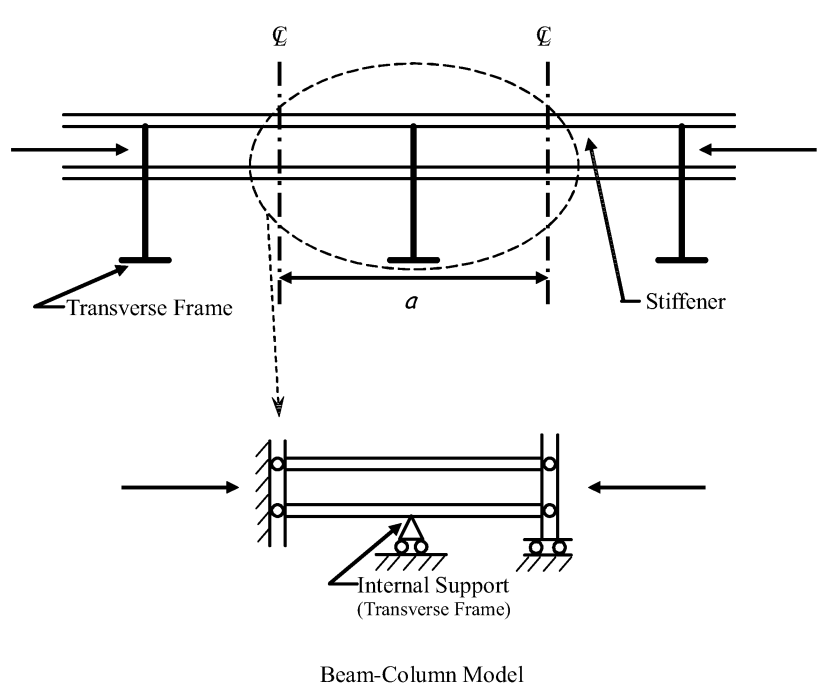

Fig. 5. An analytical model for the sectional area of a stiffened panel with boundary conditions. linear function is considered for the in-plane deformation. Therefore, the buckling reduction factor can be yielded as

$$
\phi_{u}=\frac{\sigma_{u}}{\sigma_{y}}=\frac{1}{f}\left(1+0.15 \beta^{2}\right)^{-0.5},
$$

in which

$$
\left\{\begin{array}{lr}
f=1+0.209 \lambda_{s}^{2}+0.156 \lambda_{s}^{4} & 0 \leq \lambda_{s}<1.59 \\
f=\lambda_{s}^{2} & \lambda_{s} \geq 1.59
\end{array} .\right.
$$

All the formulae listed above are used to calculate the buckling failures of a plate with stiffeners. As for the estimation of that of a plate, the following formula is adopted.

\section{Davison's formula}

Davison [9] proposed an empirical formula to deal with the buckling failure of a plate as

$$
\frac{\sigma_{u}}{\sigma_{y}}=0.23+\frac{1.16}{\beta}-\frac{0.48}{\beta^{2}}+\frac{0.09}{\beta^{3}} .
$$

It should be noted here that once the parameter, $\lambda_{s}$, in equations (1) to (3) is set to be zero, then all of them can be used to calculate the buckling failure of a plate without stiffeners as equation (4).

\section{Approach used to analyze yielding failure}

When the structural members are subjected to yielding loads, if there exists no crack in member, in general, the elasto-plastic behavior can be illustrated as Fig. 6(a). Based on the assumption, the average yielding stress used in the paper for the plate with stiffeners can be yielded as

$$
\sigma_{y a}=\frac{\sigma_{y p} \cdot A_{p}+\sigma_{y s} \cdot A_{s}}{A_{s}+A_{p}},
$$

in which $A_{p}$ and $A_{s}$ represent the sectional areas of a plate and a stiffener, respectively; $\sigma_{y p}$ and $\sigma_{y s}$ denote the yielding stresses of a plate and a stiffener, respectively.

\section{Approach used to analyze shearing failure}

As for the buckling failure due to shear forces existing in a panel member of rectangular section between two stiffeners as shown in Fig. 6(b), an assumption should be noted that the sectional area of a plate with stiffener remain unchanged until the buckling of the panel subjected to shearing effects yields; therefore, when the initial imperfection existing at the center of the rectangular panel and the simple supported bound- 
ary conditions given at the edges of the panel are both considered, the shear reduction factor can be yielded as [37]

$$
\phi_{u \tau}=\frac{\tau_{u}}{\tau_{c r}}=0.9 \cdot \frac{K_{1}-\sqrt{K_{2}^{2}-4 K_{1} K_{3}}}{2 K_{1}},
$$

in which $\tau_{u}$ and $\tau_{c r}$ denote the ultimate and critical shearing stresses, respectively; the constants, $K_{1}=$ $0.0126 \tau_{y}, K_{2}=0.1067 \tau_{y}+\tau_{c r}$, and $K_{3}=1.084 \tau_{y}$, in which $\tau_{y}=\frac{\sigma_{y a}}{3}$ and $\sigma_{y a}$ is the average yielding stress as de scribed in equation (5). It should be noted that the critical shearing stress, $\tau_{c r}$, is yielded based on the elastic shearing buckling effect and is obtained by modifying the plastic coefficient, that is,

$$
\tau_{c r}=\left\{\begin{array}{ll}
\tau_{E}, & \text { for } \frac{\tau_{E}}{\tau_{y}} \leq 0.5 \\
\tau_{y}\left(1-\frac{\tau_{y}}{4 \tau_{E}}\right), & \text { for } \frac{\tau_{E}}{\tau_{y}} \leq 0.5
\end{array},\right.
$$

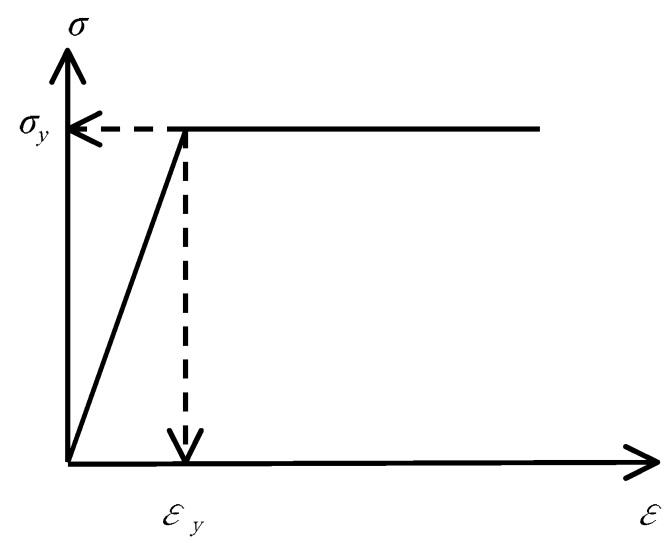

(a)

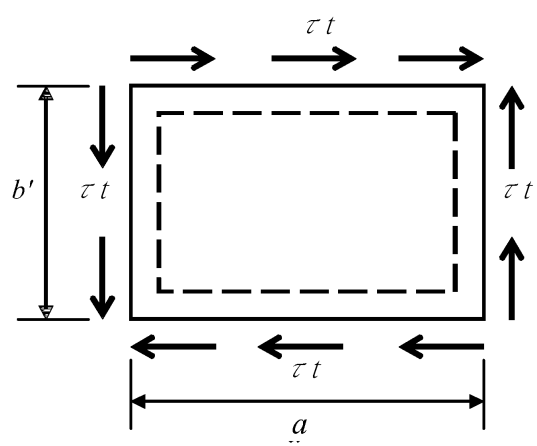

(b)

Fig. 6. (a) The elasto-plastic behavior of the structural member, (b) the shear forces existing in a panel member of rectangular section. in which the elastic shearing stress, $\tau_{E}$, can be expressed as

$$
\tau_{E}=k_{\tau} \cdot \sigma_{E}
$$

In equation (8), $\sigma_{E}=\frac{\pi^{2} E}{12(1-v)}\left(\frac{t}{b^{\prime}}\right)^{2}$ where $E$ and $v$ are the Young's modulus and the Poisson's ratio, respectively; parameters $t$ and $b^{\prime}$ are illustrated in Fig. 6 (b); $k_{\tau}$ is defined as

$$
k_{\tau}= \begin{cases}5.34+4.0\left(\frac{b^{\prime}}{a}\right)^{2}, & \text { for } \frac{a}{b^{\prime}} \geq 1 \\ 5.34+4.0\left(\frac{a}{b^{\prime}}\right)^{2}, & \text { for } \frac{a}{b^{\prime}}<1\end{cases}
$$

or

$$
k_{\tau}=\frac{\pi^{2}}{32 \alpha^{2} \lambda}
$$

in which $\alpha=\frac{a}{b^{\prime}}, \quad$ and $\lambda=\frac{\alpha^{4}}{81\left(1+\alpha^{2}\right)^{4}}\left[1+\frac{81}{625}+\right.$ $\left.\frac{81}{25}\left(\frac{1+\alpha^{2}}{1+9 \alpha^{2}}\right)^{2}+\frac{81}{25}\left(\frac{1+\alpha^{2}}{9+\alpha^{2}}\right)^{2}\right] \cdot k_{\tau}$ is selected the smaller among calculated values of the two equations.

\section{Methods to calculate ultimate longitudinal strength}

The problem of calculating the ultimate longitudinal strength of ship hull is, basically, a kind of nonlinear elasto-plastic behavior of structural members usually with initial imperfection and residual stress. Up date, to deal with such a problem, the FEM is available; however, the preprocessing with modeling and numerical calculations needs much time and expenditure such that a fast assessment before an immediate rescue operation or that at a preliminary design stage of ship hull becomes unavailable. Since Billingsley [4] proposed a simplified calculating procedure to fix such a problem, many researchers have begun to develop the simplified approaches and carried out several experimental models to validate their accuracy and reliability. Based on beam theory, these researches constructed the relationship of bending moment and curvature, then, to calculate the ultimate bending strength of ship hull. More specifically, the initial imperfection and residual stress are considered at specified plate with stiffeners of each member to construct the stress-strain diagram, and then to calculate the bending moment by giving the curvature of section gradually. Finally the ultimate bending moment can be determined by way of the diagram of bending moment and curvature. Above all, based on the simplified procedure, Lin [29] further proposed a regression formula, in which a reduction factor exists to represent the popular and frequent used members of ship structures, to calculate the ultimate bending strength of a box 


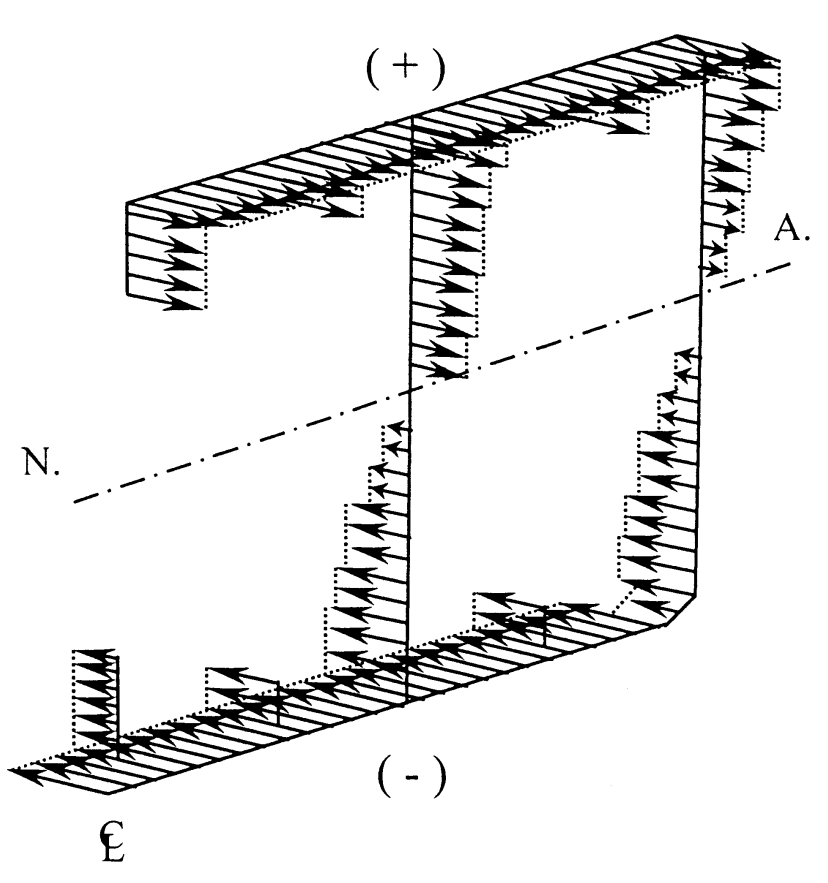

(a)

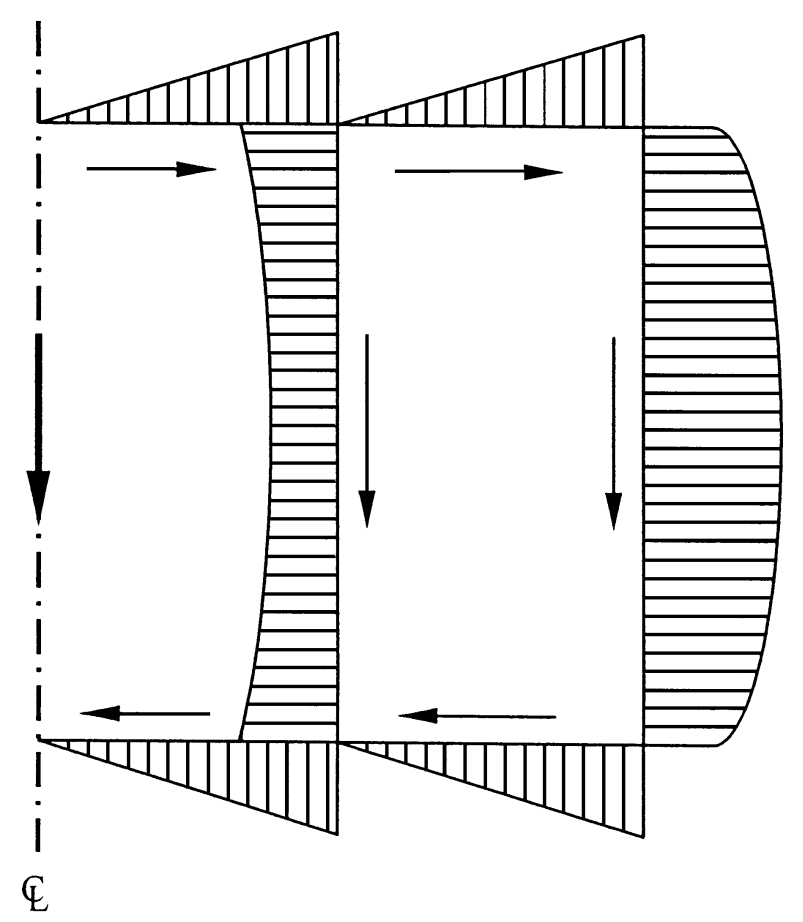

(b)

Fig. 7. (a) Normal stress distributions for a tanker, (b) shear stress distributions for a tanker. girder. Following with Lin's idea, Paik and Mansour [35] further proposed an improved simplified method, of which several useful formulae describing the ultimate longitudinal bending moment strength under sagging and hogging conditions and the ultimate horizontal bending moment were derived. In their methods, sections of structural members subjected to loadings are assumed unchanged, the compressive and tensile loading conditions adopt the ultimate stress and yielding stress, respectively, and post-buckling effect is neglected.

The present paper follows Paik et al's simplified procedures and further considers different buckling and yielding stresses, shearing stress with related bending moments, shearing stress and torsional stress due to free torque for different types of ship's sections as shown in Figs. 7 to 9. The basic assumptions for used simplified calculating procedures are:

1. the ship is floating at upright condition;

2. the section of a calculating member is unchanged when subjected to loadings;

3. the members are independent of each other when calculating the various ultimate strengths of members;

4. calculations of bending moments only concern normal stresses such as buckling and yielding effects, while those of shear and free torque effects consider shear stress and shear flow, respectively.

Therefore, those formulae for calculating ultimate vertical bending moments under sagging and hogging conditions, ultimate horizontal bending moment, ultimate shear strength and free torque assuming that no longitudinal constraint exists in the closed channel of ship section are revisited and can be yielded as follows.

\section{Ultimate vertical and horizontal bending strengths}

Based on the beam theory, the bending strength

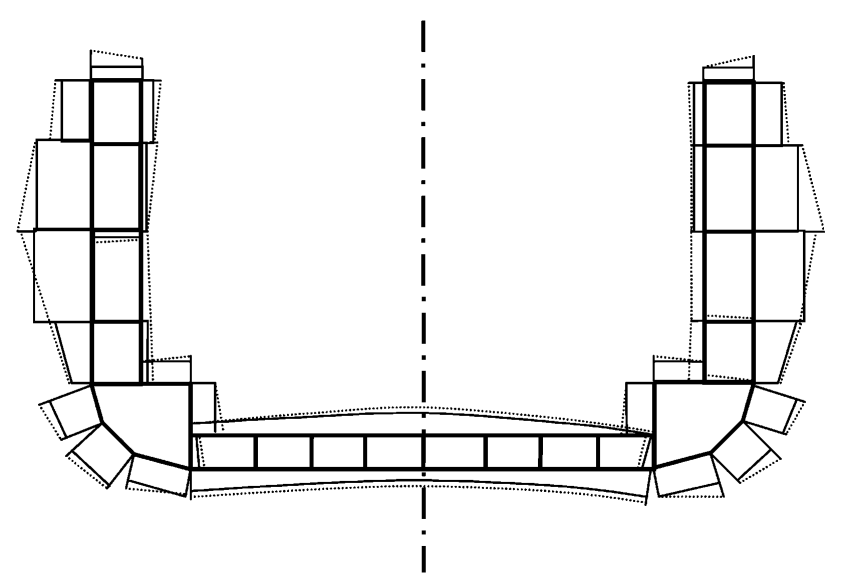

Fig. 8. Shear stress distributions for a container. 
only concerns the normal stresses; therefore, all the stress distributions can be illustrated in Fig. 10 and the related coordinate describing the hull section can be shown in Fig. 11. For lengthy of the paper, only used formulae for calculating the ultimate vertical bending moments of sagging and hogging conditions and ultimate horizontal bending moment are described in the following. Detailed derivations of those formulae can be found in Lee's work [26] for the interested readers.

(1) Ultimate vertical bending moment at sagging condition, $M_{V u s}$

The normal stress, $\sigma_{x}$, for calculating the vertical bending moment in sagging is

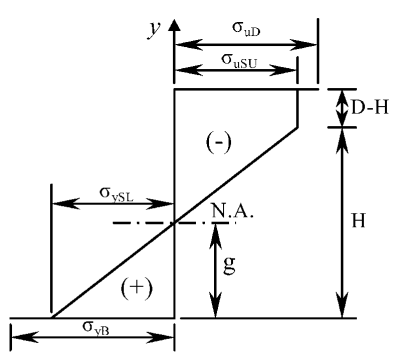

(a) Sagging Condition

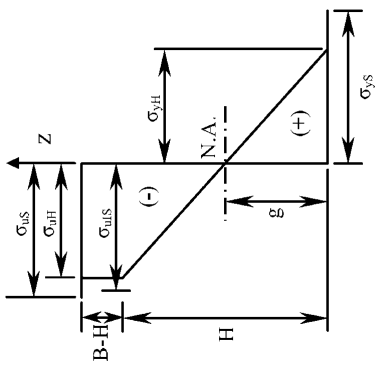

(c) Horizontal Bending Condition

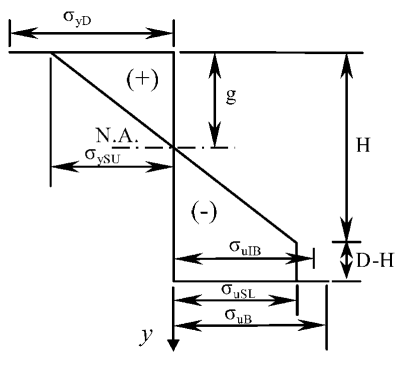

(b) Hogging Condition
(+) Tensile Stress

( ) Compressive Stress

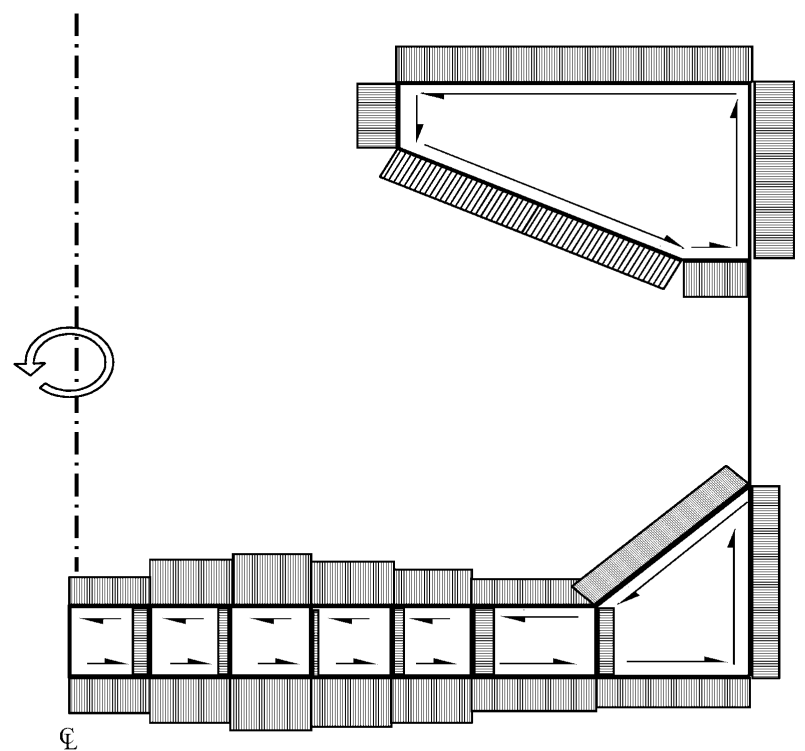

(b)

Fig. 9. (a) Shear stress distributions for a bulk carrier, (b) torsional stress distributions for a bulk carrier.
Fig. 10. Normal stress distributions for ultimate vertical and horizontal bending moment conditions.

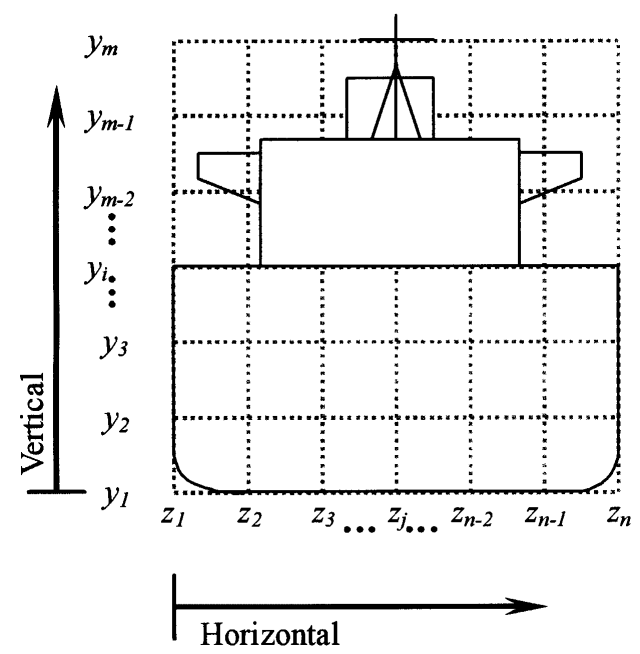

Fig. 11. The coordinate system of a hull section for calculating the ultimate vertical and horizontal bending moments. 


$$
\sigma_{x}=\left\{\begin{array}{ll}
\sigma_{y B}, & \text { for } y=y_{1}=0 \text { (outer bottom) } \\
-\frac{1}{H}\left[\left(\sigma_{u S U}+\sigma_{y S L}\right) y-H \sigma_{y S L}\right], & \text { for } 0 \leq y \leq H \\
-\sigma_{u S U}, & \text { for } H \leq y \leq D \\
-\frac{1}{H}\left[\left(\sigma_{u S U}+\sigma_{y S L}\right) y_{i}-H \sigma_{y S L}\right], & \text { for } y=y_{i}, i=2,3, \ldots,(m-1) \\
-\sigma_{u D}, & \text { for } y=y_{m}
\end{array},\right.
$$

in which $\sigma_{y B}$ represents the mean yielding stress of the outer bottom, and $\sigma_{u D}$ represents the ultimate buckling stress of deck. It should be noted that the two parameters have a linear relationship when they are gradually approaching to the neutral axis as shown in Fig. 10(a); therefore, $\sigma_{y S L}$ represents the yielding stress of a representative member between the bottom and neutral axis, and $\sigma_{u S U}$ represents the compressive stress of a representative member between the deck and neutral axis. Besides, $\int \sigma_{x} d A=0$, it means the summation of normal loads due to the normal stress applying on the section is equal to zero and thus, the position of neutral axis, $g$, can be yielded as

$$
g=\frac{\sigma_{y S L} \cdot H}{\sigma_{u S U}+\sigma_{y S L}},
$$

and

$$
H=C_{1} D+\sqrt{C_{1}^{2} D^{2}+2 C_{2} D},
$$

in which

$$
C_{1}=\frac{\left(\sigma_{u D} A_{y m}+\sigma_{u S U} \sum_{j=1}^{n} A_{z_{j}}-\sigma_{y B} A_{y_{1}}-\sigma_{y S L} \sum_{i=2}^{m-1} A_{y_{i}}\right)}{\left(\sigma_{u S U}+\sigma_{y S L}\right) \sum_{j=1}^{n} A_{z_{j}}}
$$

and

$$
C_{2}=\frac{\sum_{i=2}^{m-1}\left(A_{y_{i}} y_{i}\right)}{\sum_{j=1}^{n} A_{z_{j}}}
$$

in which $y_{i}, z_{j}, A_{y_{i}}$ and $A_{z_{j}}$ represent the coordinates of horizontal and vertical members and their corresponding area, respectively, and $D$ the height of section. Therefore, the ultimate vertical bending moment in sagging can be yielded as [35]

$$
\begin{aligned}
M_{V u s} & =-A_{y m} \sigma_{u D}(D-g)+\frac{1}{H}\left(\sigma_{u S U}+\sigma_{y S L}\right)\left[\sum_{i=2}^{m-1} A_{y_{i}}\left(g y_{i}-y_{i}^{2}\right)\right] \\
& +\sigma_{y S L}\left[\sum_{i=2}^{m-1} A_{y_{i}}\left(y_{i}-g\right)\right]-\frac{1}{2 D}\left(\sum_{j=1}^{n} A_{z_{j}}\right)(D-H)(D
\end{aligned}
$$

$$
\begin{aligned}
& +H-2 g) \sigma_{u S U}-A_{y 1} \sigma_{y B} \cdot g-\frac{H}{6 D}\left(\sum_{j=1}^{n} A_{z_{j}}\right)\left[(2 H-3 g) \sigma_{u S U}\right. \\
& \left.-(H-3 g) \sigma_{y S L}\right]
\end{aligned}
$$

(2) Ultimate vertical bending moment at hogging condition, $M_{V u h}$

Again at the hogging condition, the normal stress, $\sigma_{x}$, for calculating the vertical bending moment can be expressed as

$$
\sigma_{x}=\left\{\begin{array}{ll}
\sigma_{y D}, & \text { for } y=y_{m}=0 \text { (at deck) } \\
-\frac{1}{H}\left[\left(\sigma_{u S L}+\sigma_{y S U}\right) y-H \sigma_{y S U}\right], & \text { for } 0 \leq y \leq H \\
-\sigma_{u S L}, & \text { for } H \leq y \leq D \\
-\frac{1}{H}\left[\left(\sigma_{u S L}+\sigma_{y S U}\right) y_{i}-H \sigma_{y S L}\right], & \text { for } y=y_{i}, i=3,4, \ldots,(m-1) \\
-\sigma_{u l B}, & \text { for } y=y_{2} \text { (inner bottom) } \\
-\sigma_{u B}, & \text { for } y=y_{1} \text { (outer bottom) }
\end{array},\right.
$$

in which $\sigma_{y D}$ represents the mean yielding stress of the deck, and $\sigma_{u l B}$ as well as $\sigma_{u B}$ represent the ultimate buckling stresses of the inner and outer bottoms, respectively. Since a linear relationship exists when they are gradually approaching to the neutral axis as shown in Fig. 10(b); therefore, $\sigma_{y S U}$ represents the yielding stress of a representative member between the deck and neutral axis, and $\sigma_{u S L}$ represents the compressive stress of a representative member between the inner bottom and neutral axis. The position of neutral axis, $g$, can, thus, be yielded again as

$$
g=\frac{\sigma_{y S U} \cdot H}{\sigma_{u S L}+\sigma_{y S U}},
$$

and

$$
H=C_{1} D+\sqrt{C_{1}^{2} D^{2}+2 C_{2} D},
$$

in which

$C_{1}=\frac{\left(\sigma_{u B} A_{y_{1}}+\sigma_{u l B} A_{y_{2}}+\sigma_{u S L} \sum_{j=1}^{n} A_{z_{j}}-\sigma_{y D} A_{y_{m}}-\sigma_{y S U} \sum_{i=3}^{m-1} A_{y_{i}}\right)}{\left(\sigma_{u S L}+\sigma_{y U L}\right) \sum_{j=1}^{n} A_{z_{j}}}$

and

$$
C_{2}=\frac{\sum_{i=3}^{m-1} A_{y_{i}}\left(D-y_{i}\right)}{\sum_{j=1}^{n} A_{z_{j}}}
$$

Therefore, the ultimate vertical bending moment in hogging can be yielded as [35] 


$$
\begin{aligned}
M_{V u h} & =-A_{y_{1}} \sigma_{u B}(D-g)+A_{y_{2}} \sigma_{u l B}\left(D-y_{2}-g\right) \\
& -\frac{1}{H}\left(\sigma_{u S L}+\sigma_{y S U}\right)\left\{\sum_{i=3}^{m-1} A_{y_{i}}\left[g\left(D-y_{i}\right)-\left(D-y_{i}\right)^{2}\right]\right\} \\
& -\sigma_{y S U}\left[\sum_{i=3}^{m-1} A_{y_{i}}\left(D-y_{i}-g\right)\right]-A_{y_{m}} \sigma_{y D} \cdot g \\
& -\frac{1}{2 D}\left(\sum_{j=1}^{n} A_{z_{j}}\right)(D-H)(D+H-2 g) \sigma_{u S L} \\
& -\frac{H}{6 D}\left(\sum_{j=1}^{n} A_{z_{j}}\right)\left[(2 H-3 g) \sigma_{u S L}-(H-3 g) \sigma_{y S U}\right]
\end{aligned}
$$

(3) Ultimate horizontal bending moment,

Based on the same procedures illustrated above, the stress distribution for calculating the ultimate horizontal bending moment can be expressed as

$$
\sigma_{x}= \begin{cases}\sigma_{y S}, & \text { for } z=z_{n}=0 \text { (starboard side outer) } \\ -\frac{1}{H}\left[\left(\sigma_{u H}+\sigma_{y H}\right) z-H \sigma_{y H}\right], & \text { for } 0 \leq z \leq H \\ -\sigma_{u H}, & \text { for } H \leq z \leq B \\ -\frac{1}{H}\left[\left(\sigma_{u H}+\sigma_{y H}\right) z_{j}-H \sigma_{y H}\right], & \text { for } z=z_{j}, j=3,4, \ldots,(n-1) \\ -\sigma_{u l S}, & \text { for } z=z_{2} \text { (port side inner) } \\ -\sigma_{u S}, & \text { for } z=z_{1} \text { (port side outer) }\end{cases}
$$

in which $\sigma_{u S}$ and $\sigma_{u l S}$ represent the compressive stresses of representative members locating at port sides inner and outer (at $z=z_{1}$ and $z=z_{2}$ ), respectively; $\sigma_{y S}$ represents the yielding stress of those members locating at outer starboard side (at $z=z_{n}$ ); $\sigma_{u H}$ and $\sigma_{y H}$ represent the stresses of those between port to neutral axis and starboard to neutral axis, respectively, since both of them have a linear variation relationship when approaching to the neutral axis as shown in Fig. 10(c). The position of neutral axis can be easily yielded as

$$
g=\frac{\sigma_{y H} \cdot H}{\sigma_{u H}+\sigma_{y H}}
$$

in which

$$
\begin{aligned}
& H=C_{1} B+\sqrt{C_{1}^{2} B^{2}+2 C_{2} B}, \\
& C_{1}=\frac{\sigma_{u S} A_{z_{1}}+\sigma_{u l S} A_{z_{2}}+\sigma_{u H} \sum_{i=1}^{m} A_{y_{i}}-\sigma_{y H} \sum_{j=3}^{n-1} A_{z_{j}}-\sigma_{y S} A_{z_{n}}}{\left(\sigma_{u H}+\sigma_{y H}\right) \sum_{i=1}^{m} A_{y_{i}}}
\end{aligned}
$$

and

$$
C_{2}=\frac{\sum_{j=3}^{n-1} A_{z_{j}}\left(B-z_{j}\right)}{\sum_{i=1}^{m} A_{y_{i}}},
$$

in which $B$ represents the breadth of the section. The ultimate horizontal bending moment can, thus, be yielded as [35]

$$
\begin{aligned}
M_{H u} & =-A_{z 1} \sigma_{u S}(B-g)+A_{z 2} \sigma_{u l S}\left(B-z_{2}-g\right) \\
& -\frac{1}{H}\left(\sigma_{u H}+\sigma_{y H}\right)\left[\sum_{j=3}^{n-1} A_{z_{j}}\left\{g\left(B-z_{i}\right)-\left(B-z_{i}\right)^{2}\right\}\right] \\
& -\sigma_{y h}\left[\sum_{j=3}^{n-1} A_{z_{j}}\left(B-z_{i}-g\right)\right]-A_{z_{n}} \sigma_{s D} \cdot g \\
& -\frac{1}{2 B}\left(\sum_{i=1}^{m} A_{y_{i}}\right)(B-H)(B+H-2 g) \sigma_{u H} \\
& -\frac{H}{6 B}\left(\sum_{i=1}^{m} A_{y_{i}}\right)\left[(2 H-3 g) \sigma_{u H}-(H-3 g) \sigma_{y H}\right]
\end{aligned}
$$

\section{Ultimate shear strength}

Based on the numerical calculations of shear distributions of hull sections for the container, oil tanker and bulk carrier, it is found that the maximum shear stress almost exists in the side shell or longitudinal bulkhead as shown in Figs. 7(b), 8, and 9(a); therefore, these parts of hull sections are mainly considered to calculate the ultimate shearing strength and thus, the ultimate vertical shearing strength can be expressed as

$$
Q_{u V}=\tau_{u} \cdot A_{V},
$$

in which $\tau_{u}$ denotes the ultimate shear stress and $A_{V}$ represents the summed sectional areas of side shell and longitudinal bulkhead. Similarly, the ultimate horizontal shearing strength can be represented as

$$
Q_{u H}=\tau_{u} \cdot A_{H}
$$

in which $A_{H}$ represents the summed sectional areas of bottom shell and the closed deck.

\section{Ultimate free torque strength}

It is known that for a ship with large hatch openings, the torsion rigidity is mainly attributed to and contributed by its inner closed channels, as shown in Fig. 9(b); 
therefore, the present paper only concerns the free torque due to the sectional closed channels without longitudinal constraints and it can be represented as a sum of strengths of all the inner closed channels, that is,

$$
M_{u T}=2 \sum_{i=1}^{n} \Omega_{i} q_{u},
$$

in which $\Omega_{i}$ represents the area enclosed by the center line of channel walls for the $i$-th channel, and $q_{u}$ denotes the ultimate shear flow of the representative plate.

\section{Fully plastic capacity of sectional area}

The fully plastic capacity of hull section is usually considered for different hull materials; therefore, in this paper, the vertical and horizontal bending moment, shear force and free torque, under fully plastic state, are put into implementation. For the calculation of vertical fully plastic bending moment, as shown in Fig. 12, the neutral axis of the hull section is first determined by setting the area of upper part of the cross sectional to the effective neutral axis equal to that of lower part to the effective neutral axis. Then, the fully plastic capacity state is reached when the stresses for upper and lower areas of the neutral axis are both approaching to the yielding state and the representative yielding stress for fully plastic vertical bending moment is, thus, obtained by choosing the maximum yielding stress value at the deck component. Similarly, the representative yielding stress for fully plastic horizontal bending moment is determined from the maximum yielding stress at the side shell component. As for those representative shear force and free torque, they are determined from the maximum shear stress of the related shear section and the maximum shear flow existing in the closed channels.

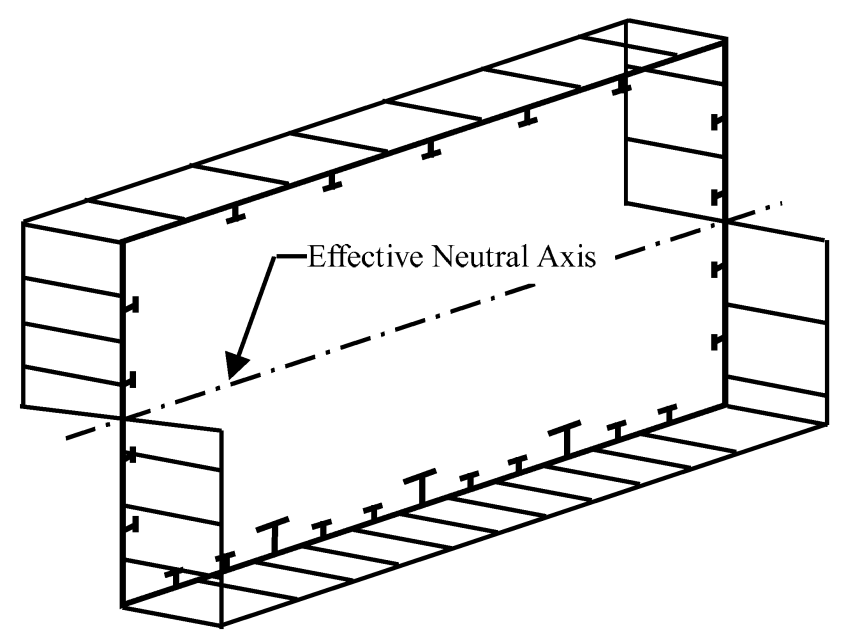

Fig. 12. An effective neutral axis of a sectional area for the fully plastic state.

\section{COMPARISONS AND VALIDATION}

\section{Comparisons of various formulae for buckling failure}

As mentioned in the above section, three formulae $[27,29,31]$ for calculating the buckling reduction factor of stiffened panels and one [9] for that of a plate have been proposed as a simplified approach; however, their adaptable ranges of applications and comparisons of each other are not clear and seldom found in the literature. Therefore, comparisons of those formulae are conducted and the results are discussed in the following.

According to the suggested dimensions and initial condition of stiffened panel from British Standard [7] and Det Norske Veritas (DNV) rules [28] and assuming that the residual stress, $\sigma_{r}$, is $20 \%$ of the yielding stress, $\sigma_{y}$; the initial imperfection of the plate, $\delta_{p}$, is $0.5 \%$ of the breadth ( $b$, as shown in Fig. 5) of stiffened panel; the initial imperfection of the stiffener, $\delta_{s}$, is $0.15 \%$ of the longitudinal length ( $a$, as shown in Fig. 5) of calculated stiffened panel; no tripping effect exists; then, the contour lines showing the relationship of two slender ratio parameters, $\lambda_{s}$ and $\beta$ for three formulae as described in equations (1) to (3) can be obtained and illustrated in Figs. 13 to 15. It is found that to estimate the reduction factor, $\phi_{u}$, Lin's and Lee's formulae are more similar especially when the slender ratio of a stiffener, $\lambda_{s}, \leq 1.59$. At the range of $\lambda_{s} \leq 1.0$, the contours of the three formulae are similar. However, when $\lambda_{s} \geq 1.5$, the contour plots of Paik's formula disperse unreasonably as shown in Fig. 14 and are quite

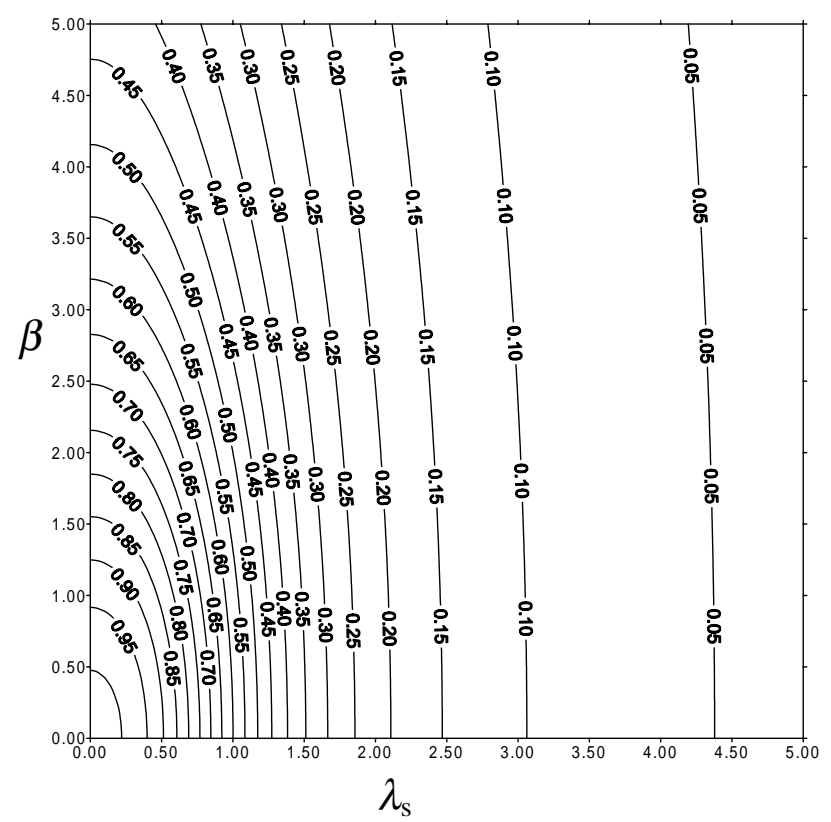

Fig. 13. Contour lines of $\lambda_{s}$ and $\beta$ for Lin's formula. 
different from those of the other twos. It means Paik's formula becomes inadequate to adopt especially when $\lambda_{s} \geq 2.0$.

As for comparisons of the reduction factors of a plate, setting every $\lambda_{s}$ in equations (1) to (3) to be zero can be used to compute the plate's reduction factors and further compare with that of Davison's formula as described in equation (4). All calculating results from their respective formulae are illustrated in Fig. 16 and it

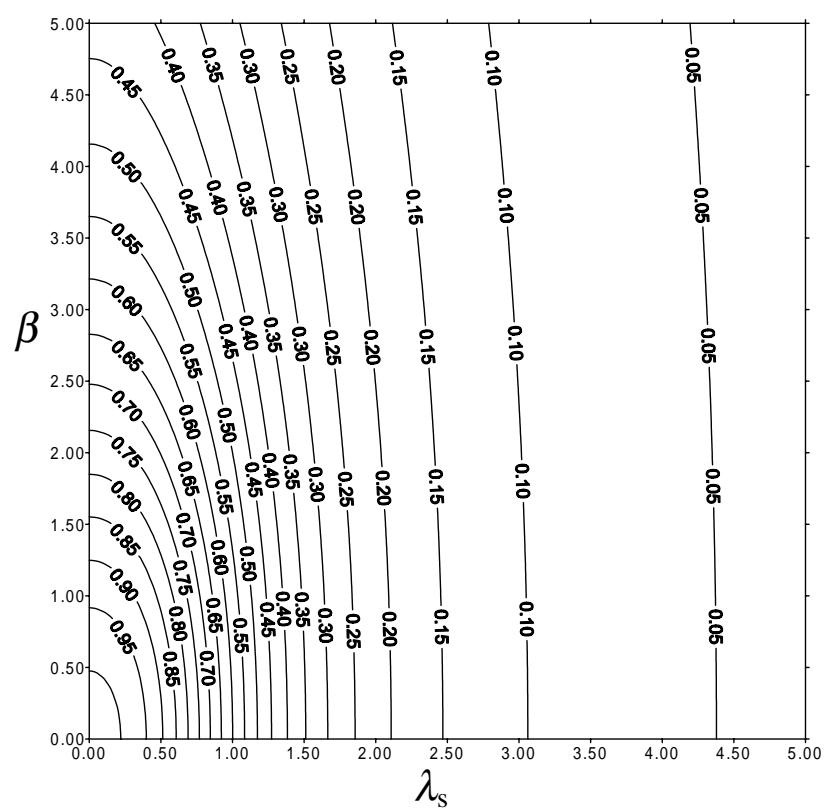

Fig. 14. Contour lines of $\lambda_{s}$ and $\beta$ for Paik's formula.

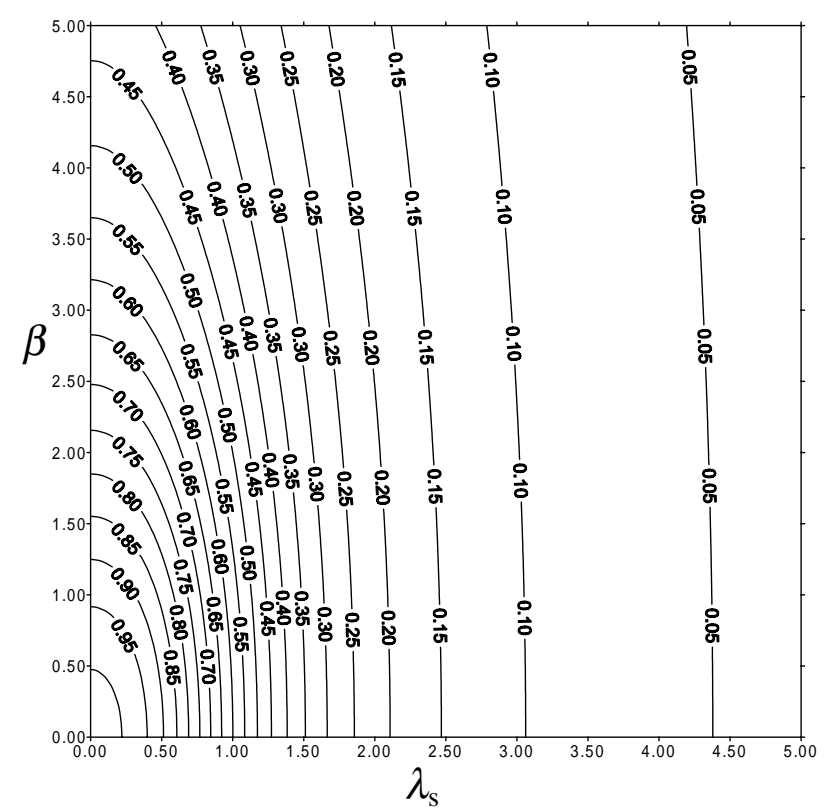

Fig. 15. Contour lines of $\lambda_{s}$ and $\beta$ for Lee's formula. is shown that when $1.0 \leq \beta \leq 1.5$, formulae of Lin's, Paik's, and Lee's show the same tendency and nearly approaching together. When $\beta \leq 1.5$, formulae of Lee and Paik are quite similar while at $\beta \geq 1.5$, those of Lin's and Paik's are approaching together and Lee's formula shows the largest among the reduction factors. However, when $\beta \leq 0.5$, the reduction factor from Lin's formula is greater than 1, it seems unreasonable. As for Davison's formula, it is suitable at the range of $\beta \geq 1.0$ and comparison results show that its reduction factor is the smallest among all when $1.3 \leq \beta \leq 4.5$.

\section{Validation of the proposed simplified approach}

Preprocessing and main frame of the numerical program

To make use of the proposed simplified approach, some preprocessing procedures for the developed numerical program are necessary and summarized as follows:

1. Members in hull section can be categorized into corner members, stiffened plate members and plate members as shown in Fig. 17. It should be noted that those areas of the deck, inner and outer bottom shells joining with side shell or bulkhead, and two end points of stiffened plate are considered as corner member.

2. A $z-y$ coordinate system as shown in Fig. 11 is set up in the hull section.

3. Numbering all members and classifying them with suitable type labels.

4. Numbering end joints of a member should correspond to the $z-y$ coordinate system.

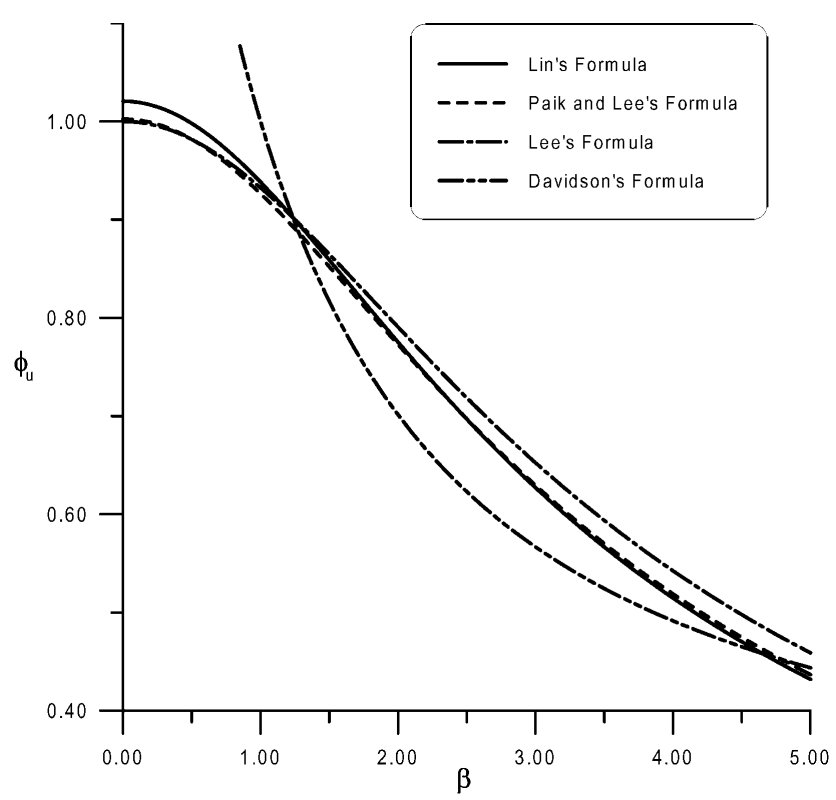

Fig. 16. Comparisons of the reduction factors of four empirical formulae. 
5. Geometry of every type of members is illustrated in Fig. 18.

All the needed input data are processed by the Excel software and stored in an xls format. Since the Excel has the graphic function, all input data can be shown graphically to check positions of nodal points of the model. The calculating and output sections are implemented by the FORTRAN language. The flow chart of the main program is shown in Fig. 19.

\section{Comparisons of numerical results with experiments}

To validate the proposed simplified approach, experiment results conducted by Nishihara [33] are used for comparison. Those experimental models with dimensions are illustrated in Fig. 20. In this figure, model label MST represents Model of Ship Tanker, MSD represents Model of Ship Double-bottom, MSB represents Model of Ship Bulk Carrier, and MSC represents Model of Container, respectively. Besides, a simplified approach proposed by Beghin et al. [3] is also included for further comparison. Characteristics of material used in the experimental models are listed in Table 1. With sagging and/or hogging conditions, there are eight kinds of testing models for calculations, and results with comparisons for buckling strength are shown in Table 2. It is shown that the present approach for calculating buckling strength at fully plastic state is as accurate as Beghin et al. [3] from results compared with each other. Relative errors of calculations of the present approach to the Beghin [3] with respect to the experimental data are all within 3\%. However, as comparing both of them with the experimental data, results from MSB model with sagging and hogging cases both show a dominant

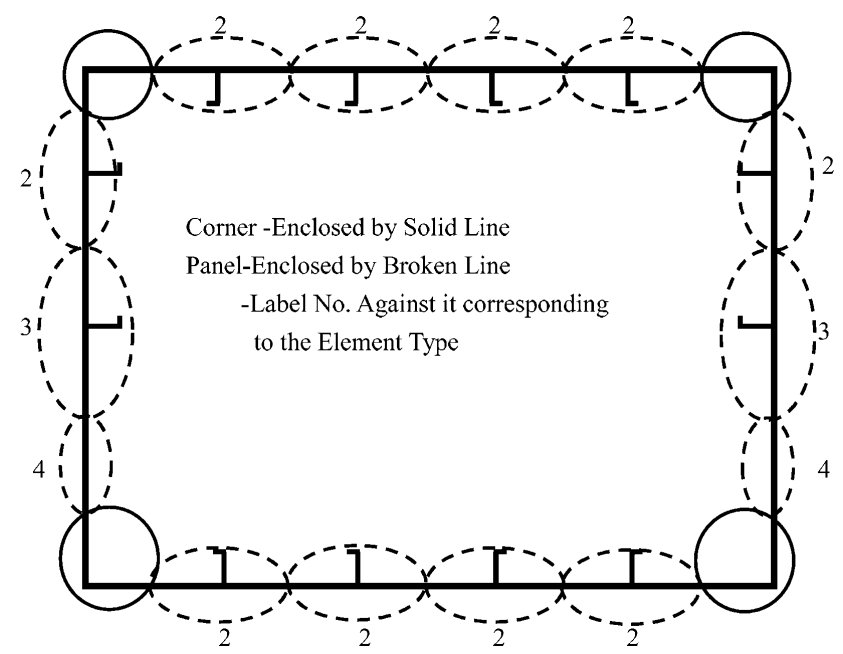

Fig. 17. Hull section members are categorized as corner, stiffened panel and plate components.

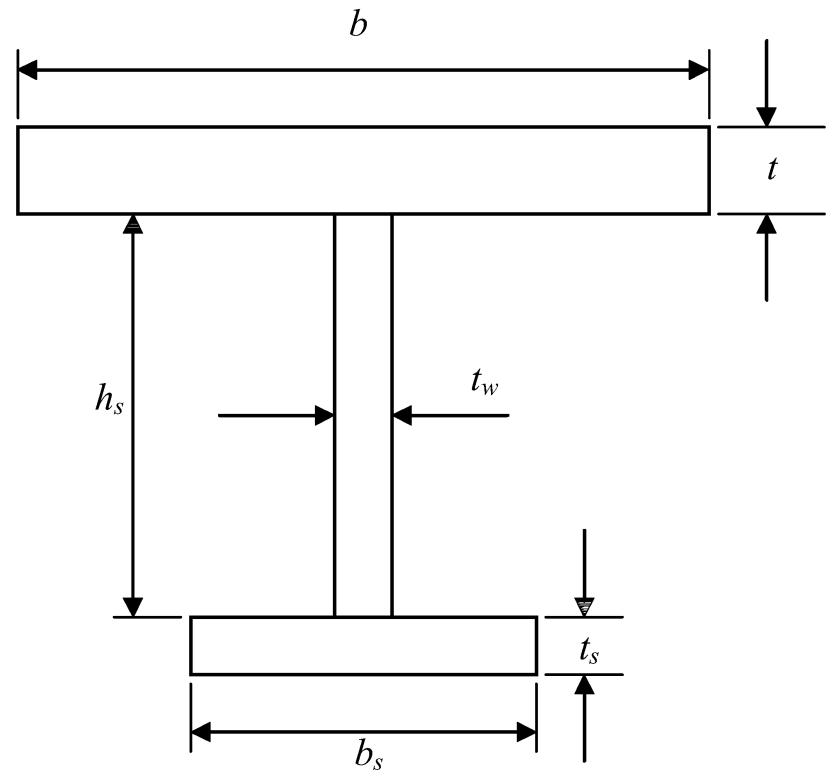

Fig. 18. The geometry of the calculated member.

Estimation of the Ultimate Longitudinal Strength of Ship Hull

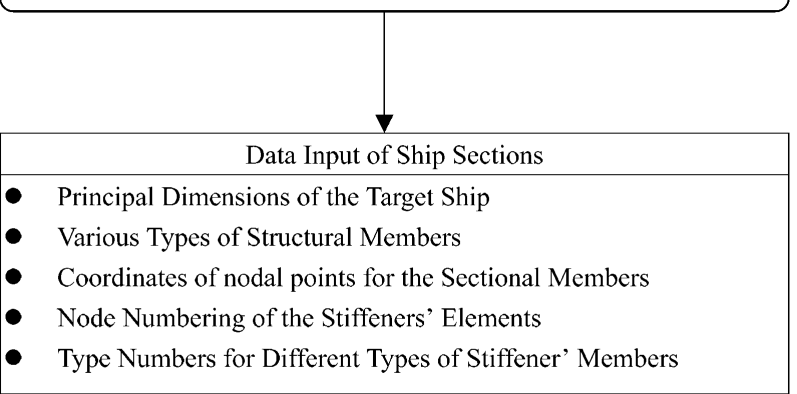

Estimations of Various Ultimate Longitudinal Strengths

- Vertical and Horizontal Bending Moments

- Vertical and Horizontal Shear Forces

- Free Torque

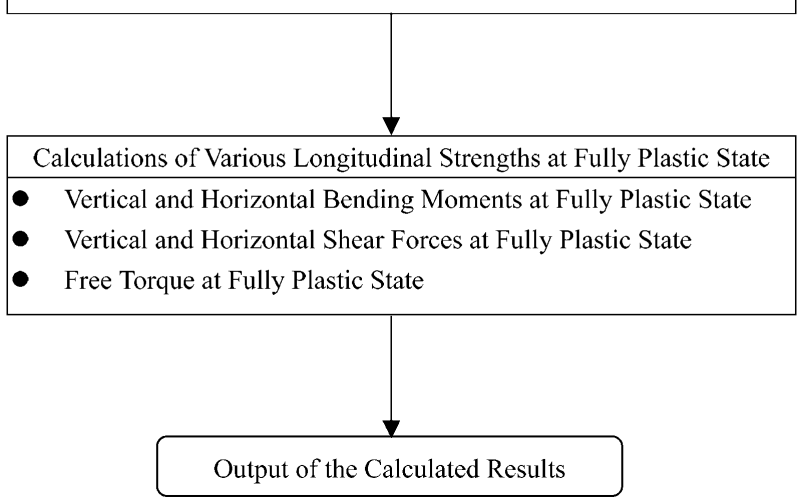

Fig. 19. The flow chart of the main program. 
Table 1. Material characteristics used in experimental models

\begin{tabular}{cccc}
\hline $\begin{array}{c}t \text { (unit: } \mathrm{mm}) \\
\text { thickness of palte }\end{array}$ & $\begin{array}{c}\sigma_{y}\left(\mathrm{Kg} / \mathrm{mm}^{2}\right) \\
\text { yielding stress }\end{array}$ & $\begin{array}{c}E\left(\mathrm{Kg} / \mathrm{mm}^{2}\right) \\
\text { Young's modulus }\end{array}$ & $\begin{array}{c}v \\
\text { Poisson's ratio }\end{array}$ \\
\hline 3.05 & 29.3 & $2.11 \times 10^{4}$ & 0.277 \\
4.35 & 26.9 & $2.12 \times 10^{4}$ & 0.281 \\
5.60 & 32.1 & $2.11 \times 10^{4}$ & 0.289 \\
\hline
\end{tabular}

Note: The material used in experimental models is mild steel.

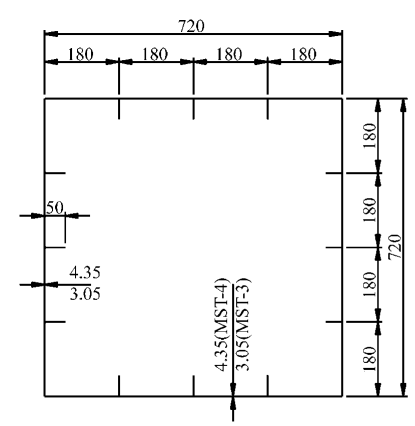

(a). Model label - MST

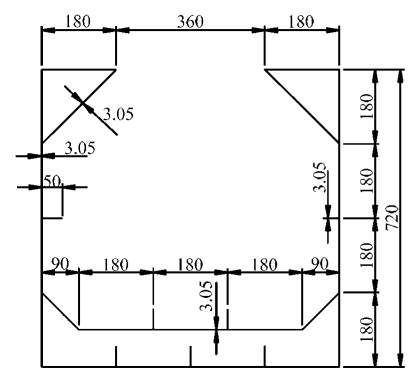

(c). Model label - MSB

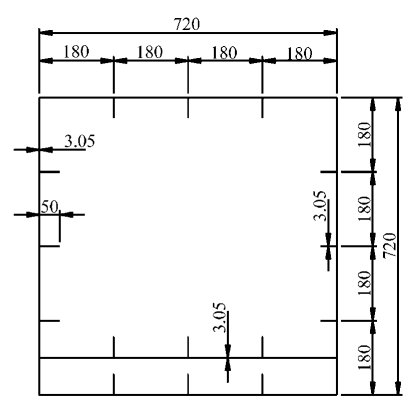

(b). Model label - MSD

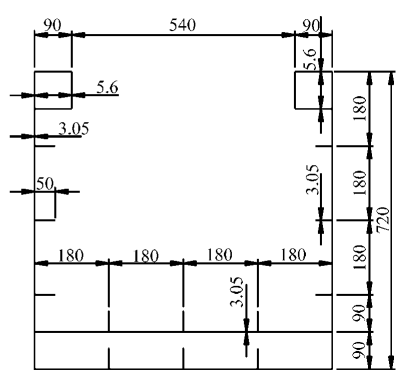

(d). Model label - MSC

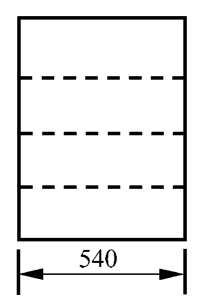

(e). Side view of the experimental model (unit: $\mathrm{mm}$ )

Fig. 20. Four experimental models with their corresponding geometry.

error. Such an error is, in our opinion, due to the ununiform scantlings of the hull section. More specifically, the MSB model is a typical kind of hull section arrangement of a bulk carrier and for calculation of the buckling strength, geometry of hull section members is very sensitive to the results especially when the wing tanks exist in the corner of hull section of a bulk carrier. Besides, it is remembered that parameters $\lambda_{s}$ and $\beta$ originally describing the slender ratios of a stiffener and a plate, respectively, now are quite hard to describe the behavior like a wing tank structures. Therefore, those methods including the present one need to be modified when dealing with the buckling strength calculation of a bulk carrier.

Lin [29] also proposed an empirical formula to calculate the ultimate vertical bending moment for hull section of box-type. The empirical formula is also used here for comparison and described in the following:

$\left\{\begin{array}{l}\frac{M_{V u s}}{M_{P}}=-0.172+1.548 \phi_{u}-0.368 \phi_{u}^{2}, \text { for sagging condition } \\ \frac{M_{V u h}}{M_{P}}=0.003+1.459 \phi_{u}-0.461 \phi_{u}^{2}, \text { for hogging condition }\end{array}\right.$

in which $\phi_{u}$ and $M_{P}$ represent the reduction factor and the vertical bending moment, respectively. Results of ultimate bending moment calculations as well as comparisons with the literature are listed in Tables 3 and 4, respectively. It should be noted that the present approach takes different reduction factors from Lin, Paik and Lee into consideration; therefore, there can have three alternatives for selection in the present method to calculate the ultimate vertical bending moments. In table 3 , it is shown that results from the present methods are accurate for cases 1 to 5 and most of them are little smaller than the experimental data except for case 5 . Such a phenomenon is due to considerations of initial imperfection and residual stress in the methods and it makes the original structural members weakened especially for cases 6 to 8 . In Table 4, although those results from Lin's empirical formula (at about $0.6 \%$ error of average only) are the most accurate, then Nishihara's $(1.113 \%)$ and Beghin's (5.71\%), to the present methods, however, it does not mean the present methods fail because some important assumptions, such like the initial imperfections of the plate and stiffener, and the residual stress, have been made in the present methods. 
Table 2. Results and comparisons of ultimate strength at vertical fully plastic state

\begin{tabular}{ccccccc}
\hline $\begin{array}{c}\text { Model } \\
\text { No. }\end{array}$ & Model Label & $\begin{array}{c}\text { Experimental } \\
\text { data [33] (ton-m) }\end{array}$ & $\begin{array}{c}\text { Béghin [3] } \\
\text { (ton-m) }\end{array}$ & $\begin{array}{c}\text { Present } \\
\text { (ton-m) }\end{array}$ & $\begin{array}{c}\text { Béghin [3]/ } \\
\text { Experiment }\end{array}$ & $\begin{array}{c}\text { Present/ } \\
\text { Experiment }\end{array}$ \\
\hline 1 & MST-1sag/hog & 94.5 & 110.00 & 109.95 & 1.164 & 1.163 \\
2 & MST-2sag/hog & 58.8 & 58.90 & 58.97 & 1.001 & 1.003 \\
3 & MSD-sagging & 60.5 & 97.30 & 97.96 & 1.608 & 1.619 \\
4 & MSD-hogging & 85.5 & 97.30 & 97.96 & 1.138 & 1.146 \\
5 & MSB-sagging & 49.1 & 86.60 & 88.03 & 1.764 & 1.793 \\
6 & MSB-hogging & 68.5 & 86.60 & 88.03 & 1.264 & 1.285 \\
7 & MSC-sagging & 113.5 & 104.20 & 103.9 & 0.918 & 0.915 \\
8 & MSC-hogging & 88.0 & 104.20 & 103.9 & 1.184 & 1.181 \\
\hline
\end{tabular}

Table 3. Calculation results of ultimate vertical bending moments

\begin{tabular}{cccccccc}
\hline $\begin{array}{c}\text { Model } \\
\text { No. }\end{array}$ & $\begin{array}{c}\text { Experimental } \\
\text { data [33] (ton-m) }\end{array}$ & $\begin{array}{c}\text { Nishihara [33] } \\
\text { (ton-m) }\end{array}$ & $\begin{array}{c}\text { Béghin [3] } \\
\text { (ton-m) }\end{array}$ & $\begin{array}{c}\text { Present with } \\
\text { Lin (ton-m) }\end{array}$ & $\begin{array}{c}\text { Present wth } \\
\text { Paik (ton-m) }\end{array}$ & $\begin{array}{c}\text { Present with } \\
\text { Lee (ton-m) }\end{array}$ & $\begin{array}{c}\text { Lin's empirical } \\
\text { formula (ton-m) }\end{array}$ \\
\hline 1 & 94.5 & 92.9 & 95.0 & 89.98 & 89.58 & 91.8 & $89.8 \mathrm{~s} /(95.0)_{\mathrm{h}}$ \\
2 & 58.8 & 59.1 & 64.2 & 57.65 & 57.29 & 56.89 & $58.8 \mathrm{~s} /(65.0)_{\mathrm{h}}$ \\
3 & 60.5 & 61.2 & 64.1 & 58.22 & 59.63 & 59.91 & 73.50 \\
4 & 85.5 & 80.8 & 87.3 & 76.31 & 76.10 & 77.48 & 81.28 \\
5 & 49.1 & 52.6 & 58.2 & 49.78 & 49.94 & 51.33 & 61.70 \\
6 & 68.5 & 74.0 & 77.2 & 45.94 & 45.93 & 45.82 & 68.16 \\
7 & 113.5 & 96.8 & 103.0 & 89.84 & 89.56 & 90.43 & 76.30 \\
8 & 88.0 & 84.5 & 93.2 & 69.88 & 69.76 & 70.44 & 84.29 \\
\hline
\end{tabular}

Note: s: sagging condition; h: hogging condition.

Table 4. Comparisons of various ultimate vertical bending moment calculations

\begin{tabular}{ccccccc}
\hline $\begin{array}{c}\text { Model } \\
\text { No }\end{array}$ & $\begin{array}{c}\text { Nishihara [33] } \\
\text { / Experiment }\end{array}$ & $\begin{array}{c}\text { Béghin [3] } \\
\text { / Experiment }\end{array}$ & $\begin{array}{c}\text { Present-Lin } \\
\text { / Experiment }\end{array}$ & $\begin{array}{c}\text { Present-Paik } \\
\text { / Experiment }\end{array}$ & $\begin{array}{c}\text { Present-Lee } \\
\text { / Experiment }\end{array}$ & $\begin{array}{c}\text { Lin's formula } \\
\text { / Experiment }\end{array}$ \\
\hline 1 & 0.983 & 1.005 & 0.952 & 0.948 & 0.971 & 1.005 \\
2 & 1.005 & 1.092 & 0.980 & 0.923 & 0.951 & 1.000 \\
3 & 1.012 & 1.060 & 0.962 & 0.986 & 0.990 & 1.215 \\
4 & 0.945 & 1.021 & 0.893 & 0.890 & 0.906 & 0.951 \\
5 & 1.071 & 1.185 & 1.014 & 1.017 & 1.045 & 1.257 \\
6 & 1.080 & 1.127 & 0.671 & 0.671 & 0.669 & 0.995 \\
7 & 0.853 & 0.907 & 0.792 & 0.789 & 0.797 & 0.672 \\
8 & 0.960 & 1.059 & 0.794 & 0.793 & 0.800 & 0.958 \\
\hline
\end{tabular}

Validation of the proposed approach with a VLCC

To further validate the proposed approach for a practical ship, a real case study of a VLCC, namely "Energy Concentration", in [41] is used here for comparison and validation. The principal dimensions of the VLCC are illustrated in Table 5. The geometry of stiffeners at hull section of this ship is shown in Fig. 21. Two hundreds and eighty five elements with 291 nodes are used in modeling for calculations. The output results from the self-developed program include ultimate vertical bending moments with hogging and sagging, fully plastic vertical and horizontal bending moments, ultimate vertical and horizontal shear stresses, fully plastic vertical and horizontal shear stresses and ultimate free torque of hull section. These results are also used to compare with those from previous studies $[17,41,35]$ and they are listed in Table 6. It is shown that except for the result of ultimate vertical bending moment in hogging, those of others are quite closed to 
Table 5. Principal dimensions of a VLCC

\begin{tabular}{ll}
\hline \multicolumn{2}{c}{ VLCC "Energy Concentration" } \\
\hline Length, overall & $326.75 \mathrm{~m}$ \\
Length, between perpendiculars & $313.0 \mathrm{~m}$ \\
Breadth, molded & $48.19 \mathrm{~m}$ \\
Depth, molded & $25.2 \mathrm{~m}$ \\
Draft, summer extreme & $19.597 \mathrm{~m}$ \\
Gross tonnage & 98,894 tons \\
Deadweight & 216,269 tons \\
Machinery & Steam turbine \\
\hline
\end{tabular}

those of published literatures. It should be note that the calculating errors of the present approach to Paik's approach [35] are within 5.2\% except for the case of ultimate vertical bending moment in hogging (12.28\%). Besides, the current approach is more available as compared with the literatures $[17,41,35]$ since it can be used to calculate other related longitudinal strengths.

\section{CONCLUSIONS}

In this paper, a simplified approach combined with a numerical program has been successfully developed to predict the longitudinal ultimate strength of ships. A comparison of buckling strength calculations with experimental data and published literatures has shown the adaptability and limitation of those available formulae used in ship structural design. Comparisons of ultimate strength calculation results obtained from the proposed approach with experimental data and those from published literatures have shown that the current approach is acceptable for estimations of ultimate bending moments in sagging or hogging with and without at fully plastic state. A further comparison of the current approach with published literatures for a practical very large crude carrier has not only validated the proposed simplified approach but also shown its accuracy. The proposed approach with the available program can, thus, be used as a fast-evaluated tool to estimate the longitudinal ultimate strength of ships especially at the preliminary stage of structural designs due to its simplicity. In addition, further studies, such as estimations of residual strength of ships after grounding or collision and the corrosion strength assessment of aging ships, can be carried out based on the current approach.

\section{ACKNOWLEDGEMENTS}

The authors would like to express their thanks to the United Ship Design and Develop Center for their financial support under Contract Number: USDDC- 221

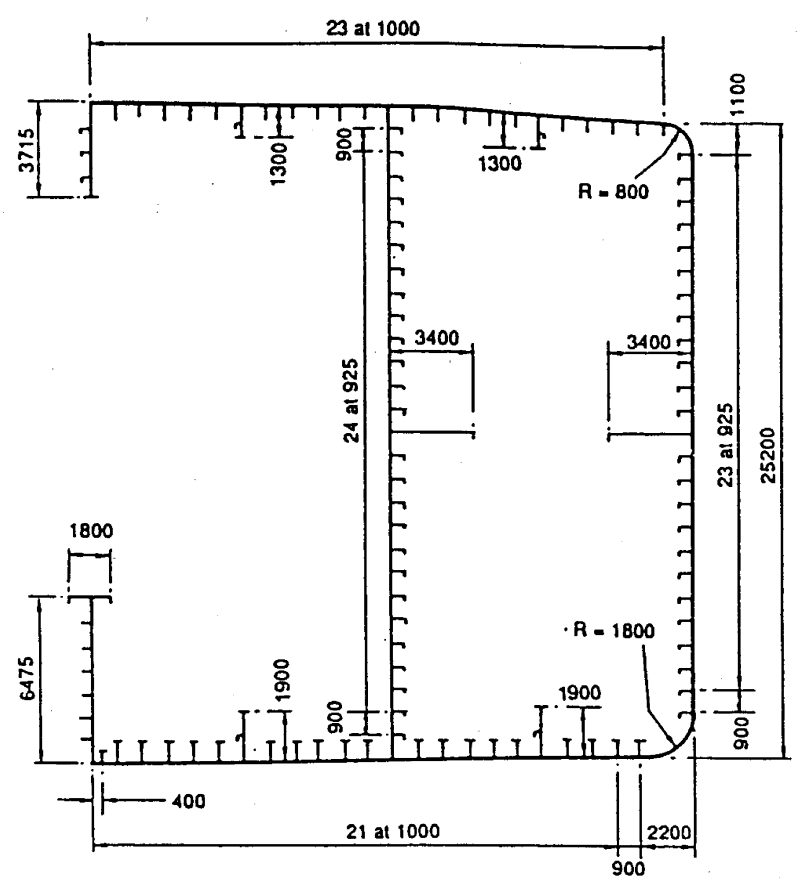

(a)

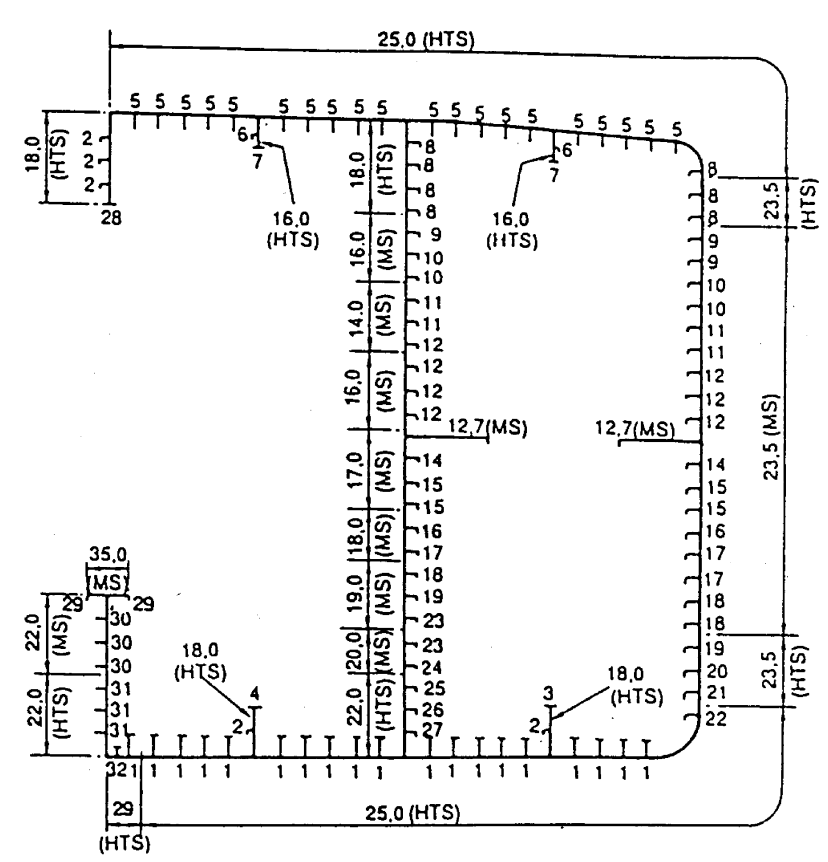

(b)

Fig. 21. (a) The geometry of hull section of a very large crude carrier [41], (b) the geometry of stiffeners at hull section of a very large crude carrier [41].

-T452. In addition, our thanks also go to Professor W. $\mathrm{H}$. Wang for some valuable discussion on this work. 
Table 6. Calculation results of the present approach and comparisons with previous studies

\begin{tabular}{|c|c|c|c|c|}
\hline & $\begin{array}{c}\text { Present } \\
\text { approach }\end{array}$ & $\begin{array}{l}\text { Ruthrtford and } \\
\text { Caldwell [41] }\end{array}$ & Paik et al. [35] & Gordo et al. [17] \\
\hline $\begin{array}{l}\text { Ultimate vertical } \\
\text { bending moment } \\
\text { of the hull in sagging }\end{array}$ & $1.9807 \mathrm{E}+12$ & $1.90 \mathrm{E}+12$ & $1.916 \mathrm{E}+12$ & $1.92 \mathrm{E}+12$ \\
\hline $\begin{array}{l}\text { Ultimate vertical bending } \\
\text { moment of the hull in } \\
\text { hogging condition. }\end{array}$ & $1.8402 \mathrm{E}+12$ & $1.55 \mathrm{E}+12$ & $1.639 \mathrm{E}+12$ & $1.64 \mathrm{E}+12$ \\
\hline $\begin{array}{c}\text { Fully plastic vertical } \\
\text { bending moment }\end{array}$ & $2.445 \mathrm{E}+12$ & - & $2.31 \mathrm{E}+12$ & - \\
\hline $\begin{array}{l}\text { Ultimate horizontal } \\
\text { bending moment }\end{array}$ & $2.3604 \mathrm{E}+12$ & - & - & - \\
\hline $\begin{array}{l}\text { Fully plastic horizontal } \\
\text { Bending moment }\end{array}$ & $3.3561 \mathrm{E}+12$ & - & $3.19 \mathrm{E}+12$ & - \\
\hline $\begin{array}{l}\text { Ultimate vertical shear } \\
\text { capacity of hull }\end{array}$ & $4.43 \mathrm{E}+07$ & - & - & - \\
\hline $\begin{array}{l}\text { Fully plastic vertical } \\
\text { shear stress of the hull }\end{array}$ & $5.14 \mathrm{E}+07$ & - & $5.12 \mathrm{E}+07$ & - \\
\hline $\begin{array}{l}\text { Ultimate horizontal } \\
\text { shear stress of the hull }\end{array}$ & $6.26 \mathrm{E}+07$ & - & - & - \\
\hline $\begin{array}{l}\text { Fully plastic horizontal } \\
\text { shear stress of the hull }\end{array}$ & $6.32 \mathrm{E}+07$ & - & - & - \\
\hline $\begin{array}{l}\text { Ultimate free torque } \\
\text { capacity of the hull }\end{array}$ & $4.10833 \mathrm{E}+11$ & - & - & - \\
\hline
\end{tabular}

Note: unit of stress: $\mathrm{kN}$; unit of moment or torque: $\mathrm{kN}-\mathrm{m}$.

\section{REFERENCES}

1. Adamahak, J.C., "An Approximate Method for Estimating the Collapse of a Ship's Hull in Preliminary Design," In Proceedings, Ship Struct. Symposium, SNAME, pp. 37-61 (1984).

2. Bai, Y., Bendiksen, E., and Petersen, P.T., "Collapse Analysis of Ship Hulls," Marine Struct., Vol. 6, pp. 485507 (1993).

3. Beghin, D., Jastrzebski, T., and Taczala, M., "Renault Computer Code for Evaluation of the Ultimate Longitudinal Strength of Hull Girder," In Proceedings, International Symposium on Practical Design of Ships and Mobile Units, PRADS95, pp. 2.832-2.843 (1995).

4. Billingsley, D.W., "Hull Girder Response to Extreme Bending Moments," In Proceedings, $5^{\text {th }}$ Star Symposium, SNAME, Coronado, pp. 51-63 (1980).

5. Caldwell, J.B., "Ultimate Longitudinal Strength," RINA Trans., Vol. 107, pp. 411-430 (1965).

6. Carlsen, C.A., "A Parametric Study of Collapse of Stiffened Plates in Compression," Struct. Engin., Vol. 56B, pp. 33-40 (1980).

7. Chalmers, D.W. and Smith, C.S., "The Ultimate Longi- tudinal Strength of a Ship Hull," In Proceedings, International Symposium on Practical Design of Ships and Mobile Units, PRADS92, pp. 2.745-2.765 (1992).

8. Chen, Y.K., Lembit, M.K., Christopher, M.P., and Maciej, P.B., "Ultimate Strength of Ship Structures," SNAME Trans., Vol. 91, pp. 149-169 (1983).

9. Davidson, P.C., "Design of Plate Panels Under Biaxial Compression, Shear and Lateral Pressure," Ph.D. Dissertation, Imperical College, University of London, England (1989).

10. Dow, R.S., Hugill, R.C., Clarke, J.D., and Smith, C.S., "Evaluation of Ultimate Strength Ship Hull Strength," In Proceedings, Extreme Loads Response Symposium, SNAME, Arlington, pp. 133-147 (1981).

11. Elsharkawi, K. and Walker, A.C., "Buckling of Multibay Stiffened Plate Panels," J. Struct. Div., ASCE, Vol. 106, pp. 1695-1715 (1980).

12. Faulker, D., "A Review of Effective Plating for Use in the Analysis of Stiffened Plating in Bending and Compression," J. Ship Res., Vol. 19, pp. 1-17 (1975).

13. Faulker, D., Adamchak, J.C., Snyder, G.J., and Vetter, M.F., "Synthesis of Wedged Grillages to Withstand Compression and Normal Loads," Computers Struct., Vol. 3, pp. 221-246 (1973). 
14. Gordo, J.M. and Guedes Soares, C., "Collapse of Ship Hulls Under Combined Vertical and Horizontal Bending Moments," In Proceedings, International Symposium on Practical Design in Shipbuilding, PRADS 95, Seoul, Vol. 2, pp. 808-819 (1995).

15. Gordo, J.M. and Guedes Soares, C., "Approximate Method to Evaluate the Hull Girder Collapse Strength," Marine Struct., Vol. 9, pp. 449-470 (1996).

16. Gordo, J.M. and Guedes Soares, C., "Interaction Equation for the Collapse of Tankers and Containerships under Combined Bending Moments," J. Ship Res., Vol. 41, pp. 230-240 (1997).

17. Gordo, J. M., Guedes Soares, C., and Faulker, D., “Approximate Assessment of the Ultimate Longitudinal Strength of the Hull Girder," J. Ship Res., Vol. 40, pp. 6069 (1996).

18. Guedes Soares, C., "Design Equation for the Compressive Strength of Unstiffened Plate Elements with Initial Imperfections," J. Construct. Steel Res., Vol. 9, pp. 287310 (1988).

19. Guedes Soares, C., "Design Equation for Ship Plate Under Unaxial Compression," J. Construct. Steel Res., Vol. 12, pp. 99-114 (1992).

20. Guedes Soares, C. and Gordo, J.M., "Compressive Strength of Rectangular Plates Under Biaxial Load and Lateral Pressure," Thin-Walled Struct., Vol. 24, pp. 231259 (1996).

21. Guedes Soares, C. and Gordo, J.M., "Design Methods for Stiffened Plates Under Predominantly Uniaxial Compression," Marine Struct., Vol. 10, pp. 465-497 (1997).

22. Guedes Soares, C. and Soreide, T.H., "Behavior and Design of Stiffened Plates Under Predominantly Compressive Loads," Int. Shipbuilding Prog., Vol. 30, pp. 13-17 (1983).

23. Hansen, A.M., "Strength of Midship Section," Marine Struct., Vol. 9, pp. 471-494 (1996).

24. Hori, T., Sekihama, H., and Rashed, S.M.H., "Structural Design by Analysis Approach Applied to a Product Oil Carrier with Unidirectional Girder System," RINA Trans., Vol. 133, pp. 199-215 (1991).

25. Hughes, O.F., "Ship Structural Design: A RationallyBased, Computer-Aided, Optimization Approach," John Wiley and Sons, New York (1983).

26. Lee, J.L., "Estimation of Ultimate Longitudinal Strength and Risk Assessment for Ship Hull," Master Thesis, Department of System Engineering and Naval Architecture, National Taiwan Ocean University, Keelung, Taiwan (2000).

27. Lee, J.S., "Reliability Analysis of Continuous Structural Systems," Ph. D. Dissertation, Department of Naval Architecture and Ocean Engineering, University of Glasgow, Scotland (1989).

28. Lee, J.S. and Yang, P.D.C., "On the Reliability Assess- ment of Double Skinned Hull Structures against Ultimate Bending and Fatigue Strength," In Proceedings, International Symposium on Practical Design of Ships and Mobile Units, PRADS92, pp. 2.834-2.836 (1992).

29. Lin, Y.T., "Ship Longitudinal Strength," Ph.D. Dissertation, Department of Naval Architecture and Ocean Engineering, University of Glasgow, Scotland (1985).

30. Mansour, A., "Charts for the Buckling and Post-buckling analyses of Stiffened Plates under Combined Loading," Tech. Res. Bull., SNAME, No. 2-22, pp. 17-25 (1976).

31. Mansour A.E., Lin, Y.H., and Paik, J.K., "Ultimate Strength of Ships under Combined Vertical and Horizontal Moments," In Proceedings, International Symposium on Practical Design in Shipbuilding, PRADS 95, Seoul, Vol. 2, pp. 844-856 (1995).

32. Mansour, A.E., Yang, J.M., and Thayamball. A., “An Experimental Investigation of Ship Hull Ultimate Strength," SNAME Trans., Vol. 98, pp. 411-439 (1990).

33. Nishihara, S., "Analysis of Ultimate Strength of Stiffened Rectangular Plate-on the Ultimate Bending Moment of Ship Hull Girder," J. Soc. Naval Architects Japan, Vol. 154, pp. 367-375 (1983).

34. Paik, J.K., "Hull Collapse of An Aging Bulk Carrier under Combing Longitudinal Bending and Shearing Force," RINA Trans., Vol. 136, pp. 217-228 (1994).

35. Paik, J.K. and Mansour A.E., "A Simple Formulation for Predicting the Ultimate Strength of Ships," J. Marine Sci. Technol., Trans., SNAJ, Vol. 1, pp. 52-62 (1995).

36. Paik, J.K. and Pedersen, P.T., "A Simplified Method for Predicting Ultimate Compressive Strength of Ship Panel," Int. Shipbuilding Prog., Vol. 43, pp. 139-158 (1996).

37. Paik, J.K., Thayamballi, A.K., and Che, J.S., "Ultimate Strength of Ship Hulls under Combined Vertical Bending, Horizontal Bending and Shearing Forces," SNAME Trans., Vol. 104, pp. 31-59 (1996).

38. Paik, J.K., Thayamballi, A.K., Kim, S.K., and Yang, S.H., "Ship Hull Ultimate Strength Reliability Considering Corrosion," J. Ship Res., Vol. 42, pp. 154-165 (1998).

39. Paik, J.K., Thayamballi, A.K., and Yang, S.H., "Residual Strength Assessment of Ships After Collision and Grounding," Marine Technol., Vol. 35, pp. 38-54 (1998).

40. Rahman, M.K. and Chowdhury, M., "Estimation of Ultimate Longitudinal Bending Moment of Ships and Box Girders," J. Ship Res., Vol. 40, pp. 244-257 (1996).

41. Rutherford, S.E. and Caldwell, J.B., "Ultimate Longitudinal Strength of Ships: A Case Study," SNAME Trans., Vol. 98, pp. 441-471 (1990).

42. Smith, C., "Influence of Local Compression Failure on Ultimate Longitudinal Strength of a Ship Hull," In Proceedings, International Symposium on Practical De- 
sign in Shipbuilding, PRADS77, Tokyo, pp. 73-79(1977).

43. Valsgard, S., "Numerical Design Prediction of the Capacity of Plates in Biaxial In-plane Compression," Computers Struct., Vol. 12, pp. $729-740$ (1980).

44. Vasta, J., "Lessons Learned from Full Scale Structural Tests," SNAME Trans., Vol. 66, pp. 165 (1958).

45. Watanabe, I. and Ohtsubo, H., "Analysis of the Accident of the MV Nakhodka. Part 1. Estimation of Wave Loads," J. Marine Sci. Technol., SANJ, Vol. 3, pp. 171-
180 (1998).

46. Yao, T. and Nikolov, P.I., "Progressive Collapse Analysis of a Ship's Hull Under Longitudinal Bending," J. Soc. Naval Archit. Japan, Vol. 172, pp. 437-446 (1992).

47. Yao, T., Sumi, Y., Takemoto, H., Kumano, A., and Sueoka, H., "Analysis of the Accident of the MV Nakhodka. Part 2. Estimation of Structural Strength," J. Marine Sci. Technol., SANJ, Vol. 3, pp. 181-193 (1998). 